التحولات الاجتماعية والسياسية في الجزائر كما يعكسها الفيلم السينمائي الروائي

\title{
معركة الجزائر
}

\section{"دراسة سيميولوجية"}

الباحث: يونس محمد الحسين

باحث بمرحلة الدكتوراه بقسم علم الاجتماع كلية الآداب جامعة قناة السويس

$$
\text { إشراف }
$$

أ. د/ حسين أنور جمعة

أ. دالح صليمان عبدالعظيم.

أستاذ علم الاجتماع جامعة عين شمس أستاذ علم الاجتماع جامعة قناة السويس

\section{الملخص:}

تمدف الدراسة إلى الكشف عن واقعية وحقيقة الحياة الاجتماعية والسياسية التاريخية

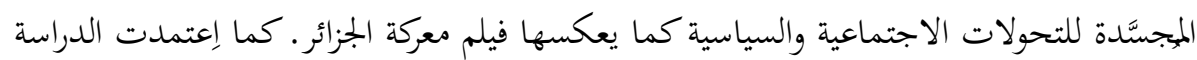

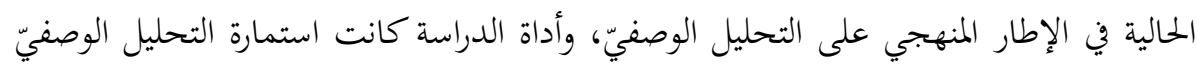

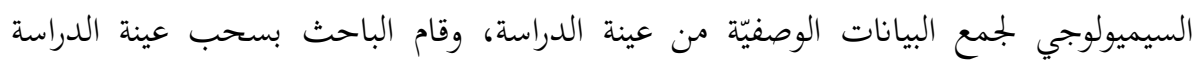

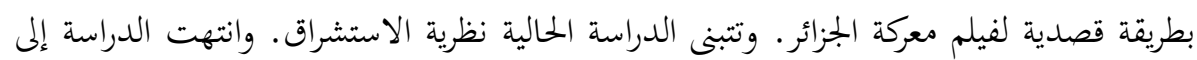

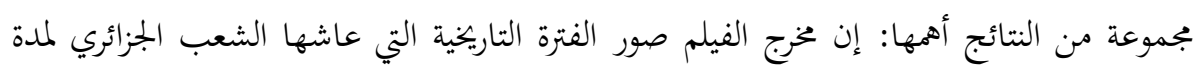

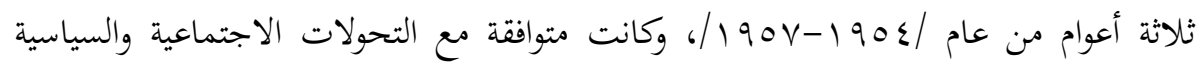

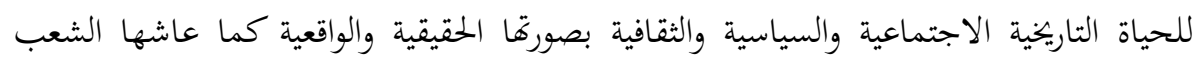

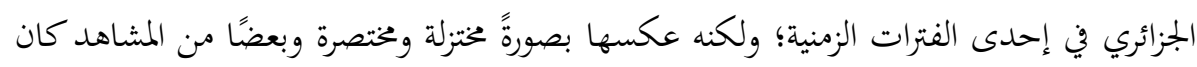

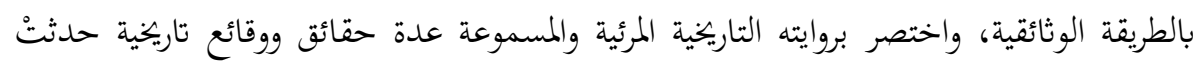

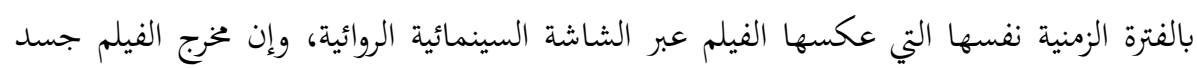


أهم الشخصيات الحقيقية التي تتحدث عنها الرواية التاريخية في فيلم معركة الجزائر. وأهم المقترحات

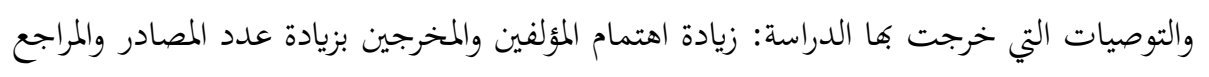

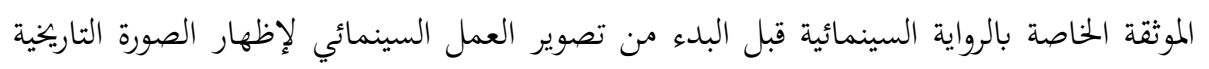

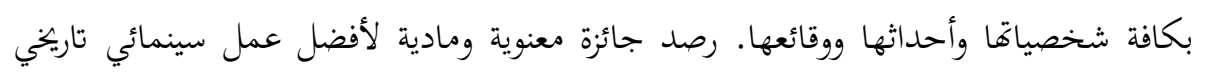

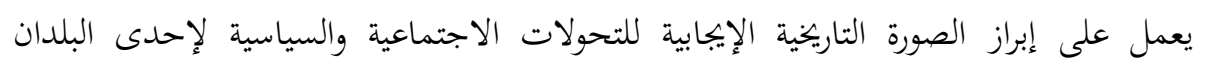
العربية.

\section{Summary:}

The study aims to reveal the realism and reality of historical social and political life embodied in social and political transformations as reflected in the film Battle of Algeria.

The current study also relied on descriptive analysis in the systematic framework، and the study tool was a semiotic descriptive analysis form to collect metadata from the study sample، and the researcher pulled out the sample of the study in a deliberate manner for the film Battle of Algeria.

The current study adopts the theory of orientalism.

The study concluded with a set of results، the most important of which is that the director of the film depicted the historical period experienced by the Algerian people for three years from 190 to $190 \mathrm{~V}$. It was compatible with the political transformations of historical social, political and cultural life in its true and realistic form as the Algerian people 
experienced at one point in time، but it reflected it in a short and concise way and some of the scenes was in the documentary way، and his historical visual and audio novel summarized several historical facts and facts that occurred in the same period of time as the films reflected through the feature film screen، and that the director of the film embodied the most important real characters that the historical novel speaks of in the film Battle of Algeria.

The most important proposals and recommendations of the study: increasing the interest of authors and directors in increasing the number of documented sources and references of the cinematic novel before starting filming the film work to show the historical image of all its characters، events and facts. Monitoring a moral and material award for the best historical film work that highlights the positive historical picture of the social and political transformations of an Arab country.

\section{مقدمة}

إن الشخصيات التاريخية والتحولات الاجتماعية والسياسية والاقتصادية تُعد مادة أساسية

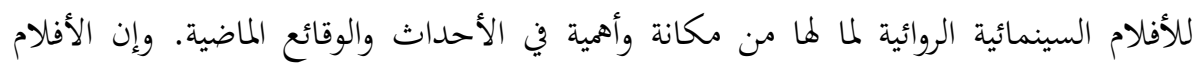

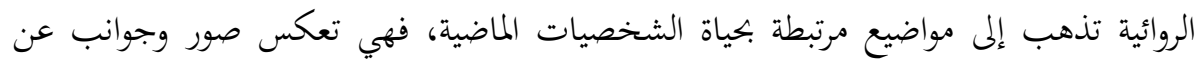

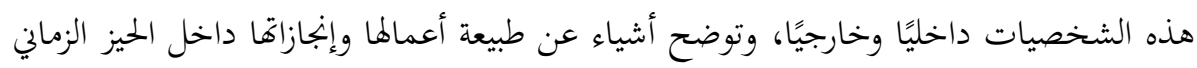

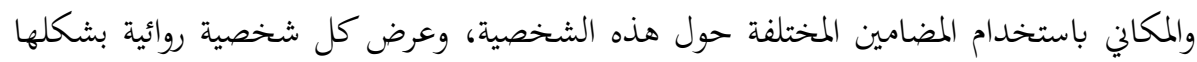

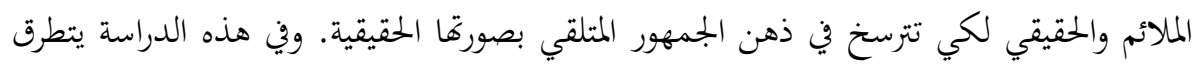


الباحث إلى دراسة الموضوع المتعلق بالتحولات الاجتماعية والسياسية في الجزائر كما يعكسها فيلم

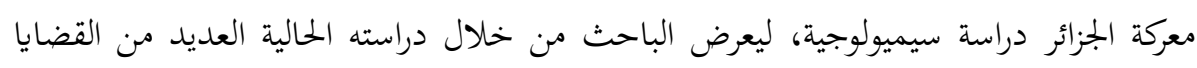

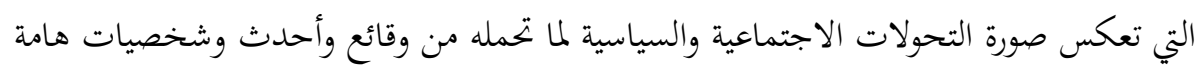

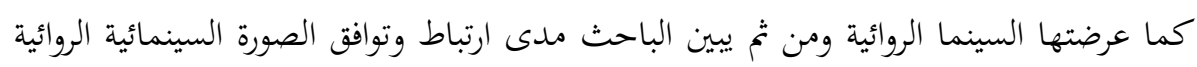

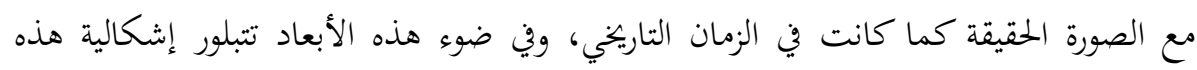

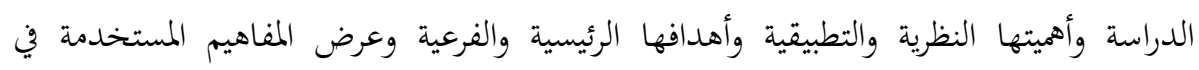

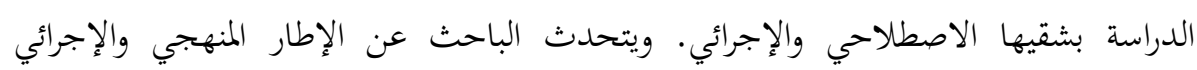

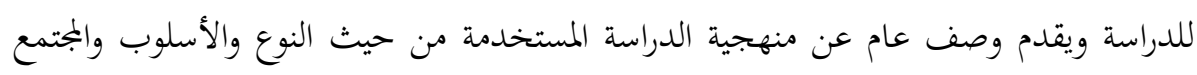

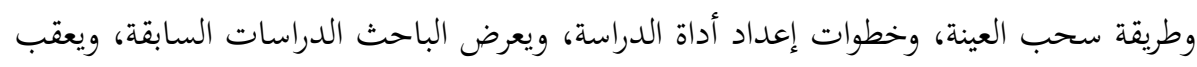

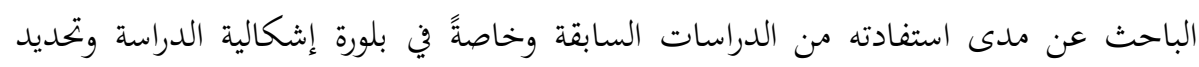

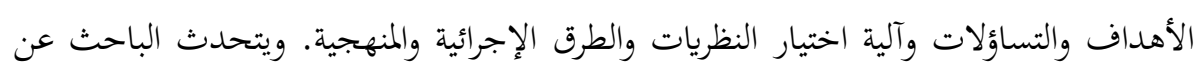

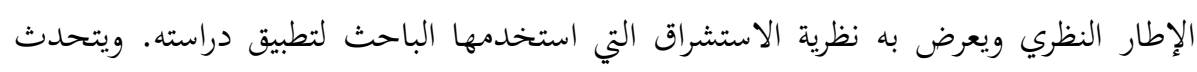

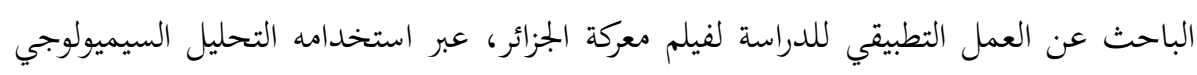
ومن ثم تفسير النتائج التي توصل لها.

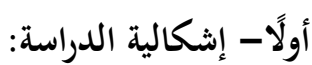

إن التحولات الاجتماعية والسياسية التي يتعرض لها العالم العربي قديمًا وحديثًا، لها تأثيرًا

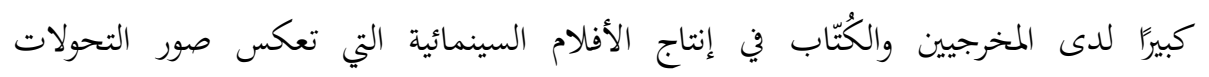

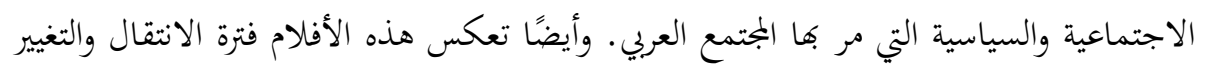
داخل الأنظمة الاجتماعية والسياسية الداخلية والخارجية في البلدان العربية ومنها الجزائر. وبناءً

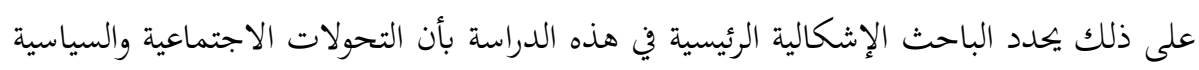

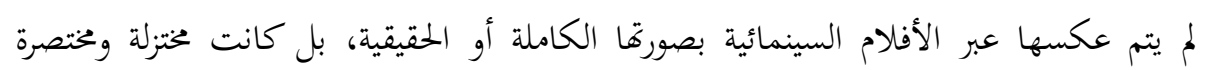
وجسدت الأفلام السينمائية التاريخية بعض الشخصيات والأحداث والوانية الوقائع عن المجتمعات العربية

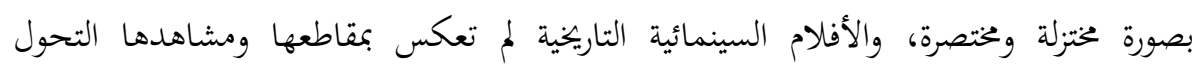

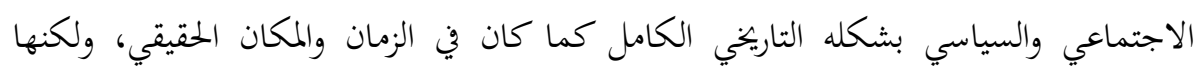
عرضت التحول الاجتماعي والسياسي بطريقة التجريد والاختزال، ويكون التجسيد للأحداث 
والوقائع كما يحبذها المؤلف والمخرج والسيناريست في إيصال صورة التحول للمتلقي بصورةً مختصرة

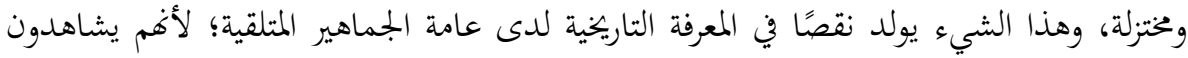

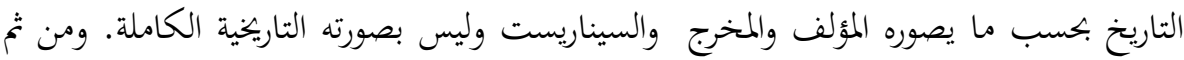
يشير الباحث بأن دراسته تسعى للوصول إلى رؤية تحليلية تاريخية عن التحولات الاجتماعية

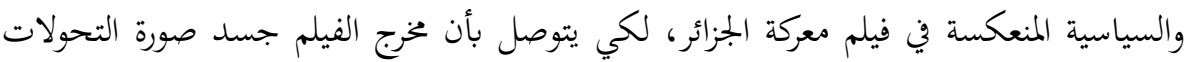

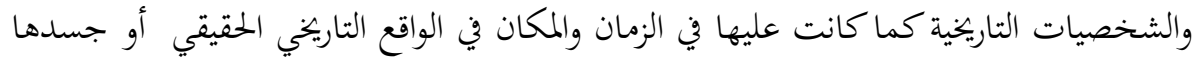
مخالفة للواقع التاريخي الذي عاشته.

ومن خلال ذلك كانت إثكالية الدراسة تتمثل في تساؤل مؤداه؛ هل السينما الجزائرية

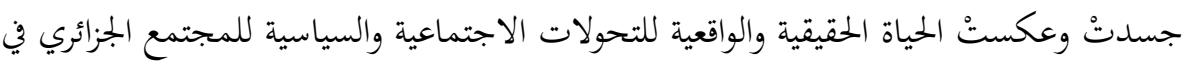

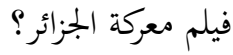

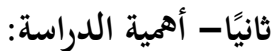

تتجلى أهمية هذه الدراسة في ناحيتين:

\section{أ - أ - الأهمية العلمية (النظرية):}

تتمثل أهمية الدراسة العلمية (النظرية) في دراسة التحولات الاجتماعية والسياسية كما

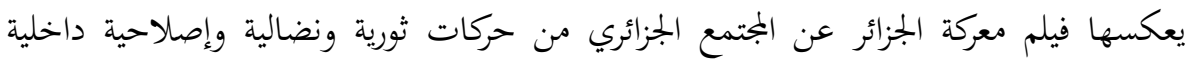
وخارجية للأنظمة الاجتماعية والسياسية، أو بمعنى آخر الوقوف على على مدى حتى حقيقة العلاقة التوافقية والترابطية للأفلام السينمائية الروائية التي جسدت صورة التحولات الاجتماعية والسياسية كما

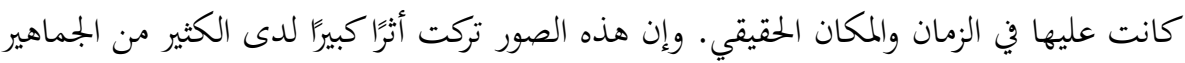

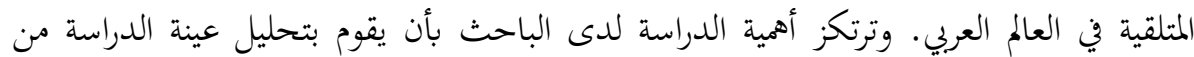

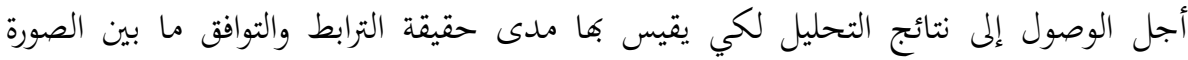
السينمائية والواقع؛ ليؤكد بأن الفيلم في عينة الدراسة ربط وجسد التحولات الاجتماعية والسياسية

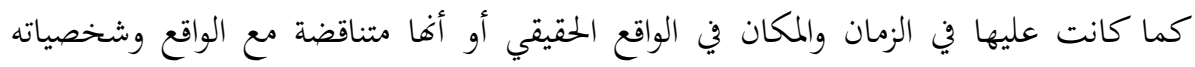


التحولات الاجتماعية والسياسية في الجزائر كما يعكسها الفيلم السينمائي الروائي...العدد الثالث والثلاثون

\section{ب- الأهمية العملية (النطبيقية):}

تتمثل الأهمية التطبيقية لمذه الدراسة في الاستفادة من النتائج التي يحصل عليها الباحث

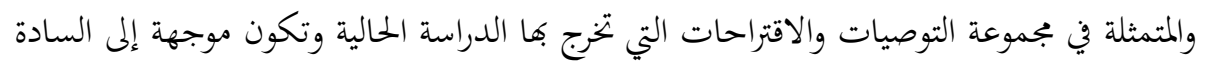

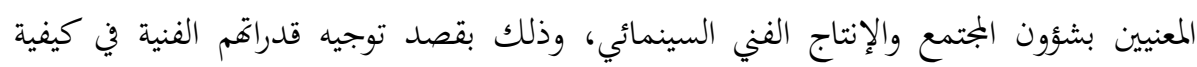
معالجة آثار التحولات الحاصلة في المجتمع العربي وبتسيدها في الأفلام السينمائية الروائية دون إضافات من أجل مصداقية الصورة السينمائية للمشاهدين والمتلقين.

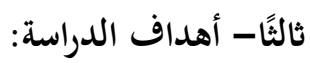

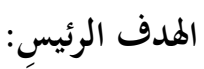

الكشف عن واقعية وحقيقة الحياة الاجتماعية والسياسية المجسسَّة للتحولات الاجتماعية والسياسية كما يعكسها فيلم معركة الجزائر عن المجتمع الجزائري. وبناء على ذلك تحددت بجموعة من الأهداف الفرعية تمثلت فيما يلي:

1- التعرف على هوية وحقيقة الشخصيات التاريخية في الصورة السينمائية المجسسَّدة كما عكسها الفيلم الروائي معركة الجزائر.

r- الكشف عن محتوى التحولات الاجتماعية زمانيًا ومكانيًا ومدى حقيقتها في الصورة السينمائية الروائية المجسسَّدة كما عكسها الفيلم الروائي معركة الجزائر.

r- رصد محتوى التحولات السياسية زمانيًا ومكانيًا ومدى حقيقتها في الصورة السينمائية الروائية المهجسَّدة مثا عكسها الفيلم الروائي معركة الجزائر.

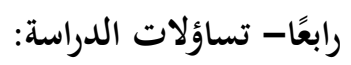

ما مدى اعتماد السينما الجزائرية في إظهار الحياة الاجتماعية والسياسية بصورتها

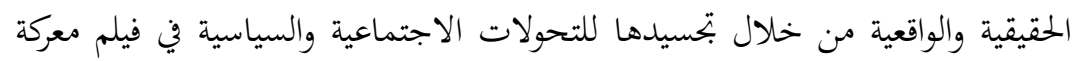

الجزائر؟ 
وفي ضوء التساؤل الرئيسي تتحدد بعض التساؤلات الفرعية تمثلت فيما يلي:

1- ما هوية الشخصيات التاريخية ومدى حقيقتها في الصورة السينمائية المجسسَّة كما عكسها

$$
\text { الفيلم الروائي معركة الجزائر؟ معيان }
$$

ץ- ما أبرز الموضوعات التي تناولتها التحولات الاجتماعية زمانيًا ومكانيًا ومدى حقيقتها في

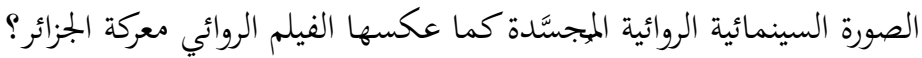

r- ما أهم الموضوعات التي تناولتها التحولات السياسية زمانيًا ومكانيًا ومدى حقيقتها في الصورة السينمائية الروائية المجرسَّدة كما عكسها الفئية الفحولم الروائي معركة الجزائر؟

خامسًا- مفاهيم الدراسة:

\section{1- مفهوم التحولات "Transformation":}

اصطلاحًا: يرى الباحث نعيم حسين القرحاني بأن مفهوم التحول؛ بأنه التغير أو

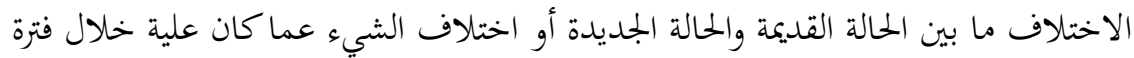
محدودة من الزمن، وحينما تضاف كلمة الاجتماعي والتي تعني وما يتعلق بالمجتمع فيصبح

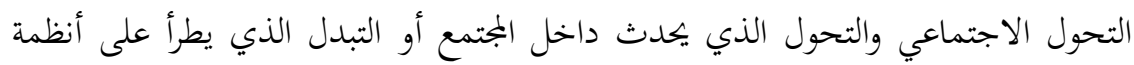

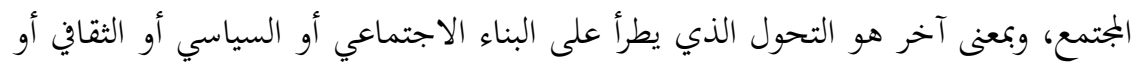

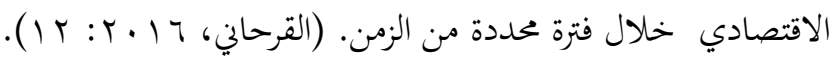

إجرائيًا: يرى الباحث بأن التحول سواء اجتماعي أو سياسي أو اقتصادي ينتج تغيرات

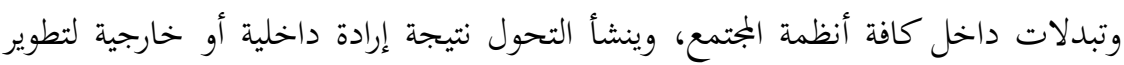

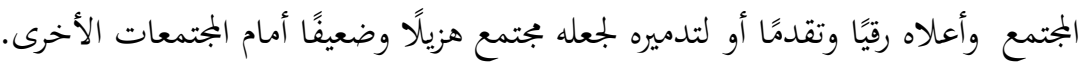

r- Feature film" الفيلم الروائيّ

اصطلاحًا: يرى الباحث إحسان العقلة بأن الفيلم الروائيّ: هو أحد الأنواع التي تستند

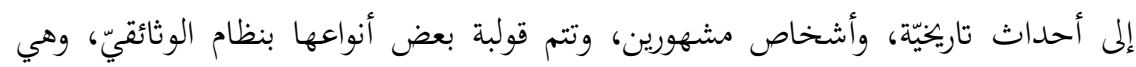


رائدة لمجمل الأحداث التي حدثت في مناطق الشرق الأدنى، والحضارة الغربيّة، وشرق آسيا،

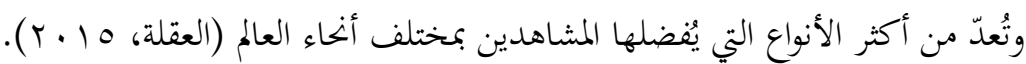

إجرائيًا: يرى الباحث بأن الفيلم الروائيّ يعكس الرواية أو القصة التي عالجها المؤلف أو

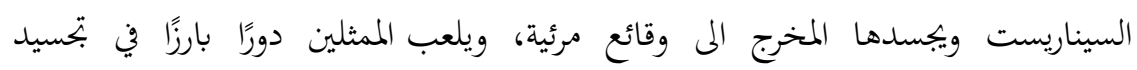

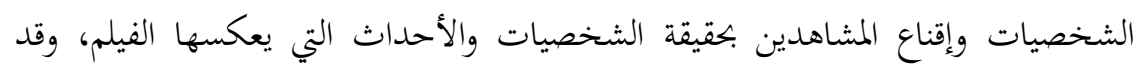

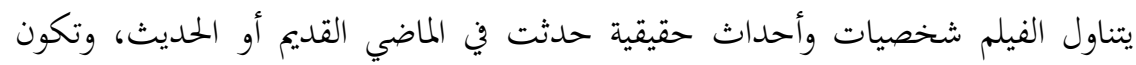

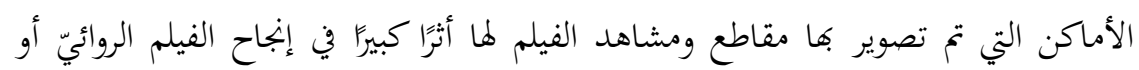
إفشاله.

\section{سادسًا- الإجراءات المنهجية:}

1 - أسلوب الدراسة: يعتمد الباحث في هذه الدراسة على الأسلوب الوصفي التحليلي،

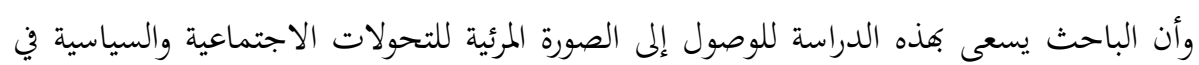

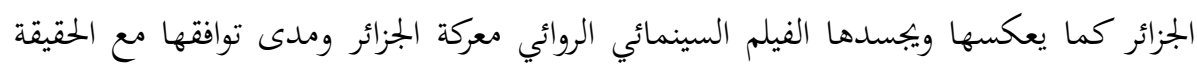

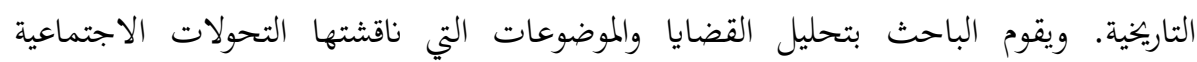
والسياسية في الجزائر بوصفه لها متغيرًا مستقلاً ويحلل هذه التحولات عبر الأفلاميلام السينمائية الروائية

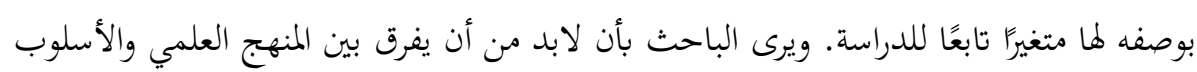

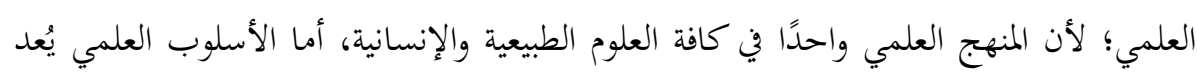

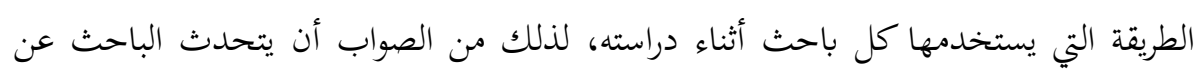
أساليب البحث العلمي وليس مناهج البحث العلمي.

r- بجتمع وعينة الدراسة: إن بجتمع الدراسة يتمثل بالمجتمع الجزائري لفترة زمنية محددة

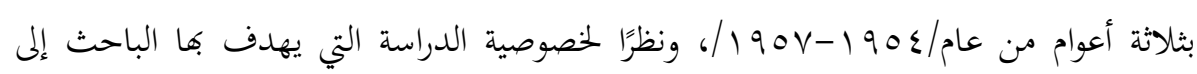
الكشف عن واقعية وحقيقة الصورة المجسمَّدة للتحولات الاجتماعية والسياسية كما يعكسها الفئل الفيلم السينمائي الروائي معركة الجزائر، لذلك اختار الباحث عينة الدراسة بالطريقة القصدية لفئدة لفيلم معركة 
r- أداة الدراسة: فإن الأداة والتقنية المناسبة التي استخدمها الباحث بدراسته هي استمارة التحليل الوصفيّ السيميولوجي لعينة الدراسة.

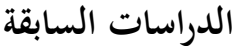

1- دراسة عياد زويرة (9 ( • ب) بعنوان "السينما التسجيلية وصورة نضال المجتمع الجزائري". تكمن أهمية هذه الدراسة في التركيز على أهمية الندوة العلمية للسينما والمجتمع والعلاقة

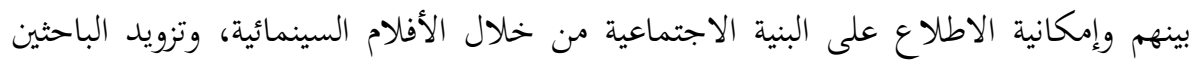
بحقائق عن النظم الاجتماعية حديثًا وقديمًا.

ومن أهم تساؤلات الدراسة؛ حيث طرح الباحث عددًا من التساؤلات يحاول من خلالها إيجاد إجابة لها: (1) ما هي سمات السينما التسجيلية في أعمال المخرجين الفرنسيين والكولونيالين

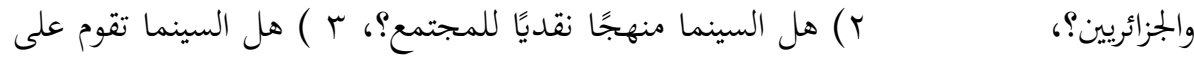

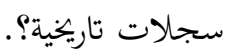

وقد تبين أن الإطار النظري للدراسة تحدث عن: تاريخ السينما، والثورة التحريرية، والمجتمع الجزائري.

كما اعتمد الباحث في الإطار المنهجي للدراسة على الدراسة الوصفية التحليلية السيميولوجية ليقدم رؤية علمية منهجية عن دراسته، واستخدم الباحث طريقة اختيار العينة بالطريقة القصدية للأفلام التي أخرجها المخرج روني فوتي.

انتهت الدراسة إلى مجموعة من النتائج وأهما؛ قرب العلاقة بين السينما والمجتمع يتجاوز حدود استخدام الآلة الفنية كوسيلة حديثة إلى الاستخدام الأمكن بالمقاومة السياسية والاجتماعية ولئه والثقافية.

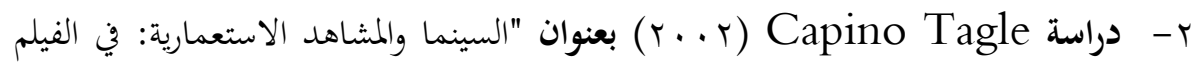

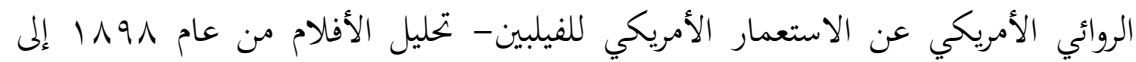
." 1919 
تكمن أهمية هذه الدراسة في الاستقصاء للتسلسل الزمني والتحليل النقدي للأفلام

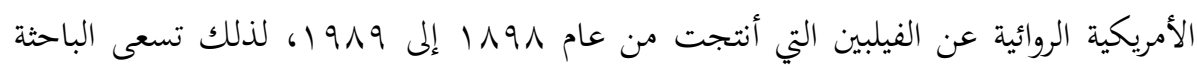
لتفسير مغزي لمذه الأفلام التسجيلية التاريخية وتحديد الأساليب الأمريكية المستخدمة كماتين التها عرضتها الأفلام السينمائية.

ومن أهم تساؤلات الدراسة؛ حيث طرحتها الباحثة عددًا من التساؤلات تحاول من

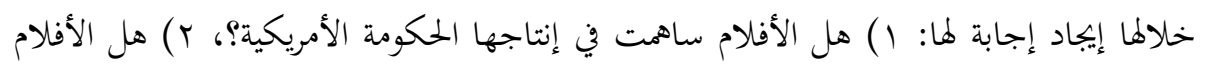
دعت للقيام بحروب باردة أخرى؟، ب) كيف كانت تاريخ العلاقة بين أمريكا والفيلبين؟.

وقد تبين أن الإطار النظري للدراسة تحدث عن: عدة مقولات نظرية لبعض العلماء والسينمائيين.

كما اعتمدت الباحثة في الإطار المنهجي للدراسة على الأسلوب التحليلي، وكانت العينة

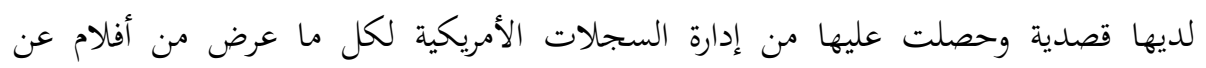

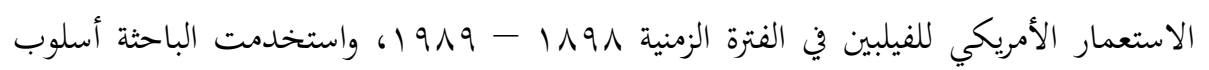

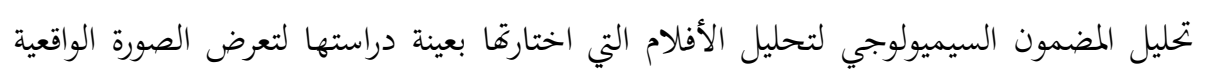
التاريخية كما عرضتها الأفلام.

انتهت الدراسة إلى مجموعة من النتائج وأهمها؛ قد أوضحت الدراسة بأن الأفلام ساهمت

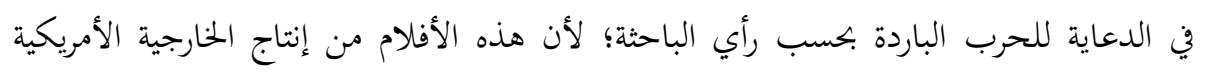

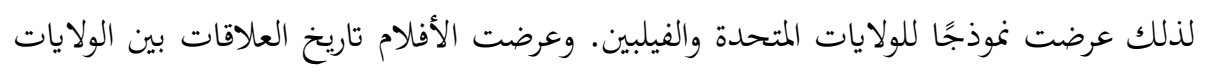

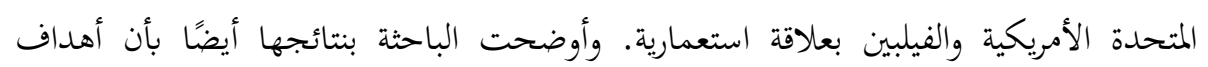
دراستها لتصحيح كتابة التاريخ والنقد به.

r- دراسة مصطفى سحاري (1/ • † بعنوان "الطرح الإعلامي لجرائم فرنسا في الجزائر دراسة تحليلية نصية لفيلم معركة الجزائر".

تكمن أهمية هذه الدراسة لدى الباحث في أن يدون الجرائم الفرنسية أثناء أيام الثورة

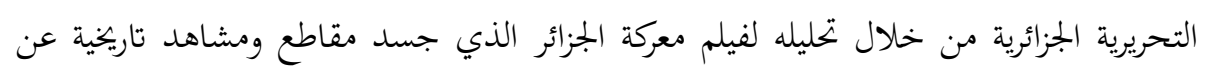


أحداث واقعية من العيار الثقيل ليكشف حجم الظلم والاستبداد الذي مارسته قوات الاستعمار الفرنسي ضد الشعب الجزائري.

ومن أهم تساؤلات الدراسة؛ حيث طرح الباحث عددًا من التساؤلات يحاول من خلالها إيجاد إجابة لها: (1) ماهي الصورة التي قدمها الفيلم عن جرائم فرنسا في الجزائر؟، ؟) ماهي

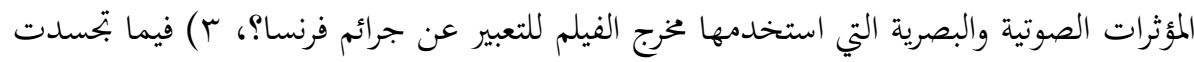
الدلالات والمعاني التي حملها الفيلم والتي عبرت عن الظلم والاستبداد الممارس ضد الشعب تربع

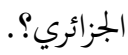

وقد تبين أن الإطار النظري للدراسة تحدث عن: نظرية النص لدى رولان بارث.

كما اعتمد الباحث في الإطار المنهجي للدراسة على الأسلوب التحليلي السيميولوجي،

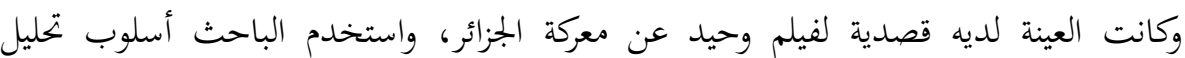

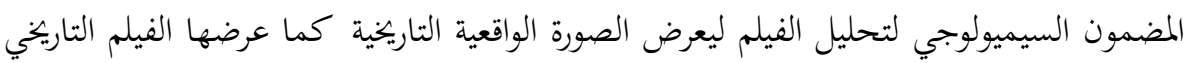

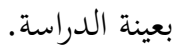

انتهت الدراسة إلى مجموعة من النتائج وأهمها؛ الصور التي عكسها المخرج عن وحشية

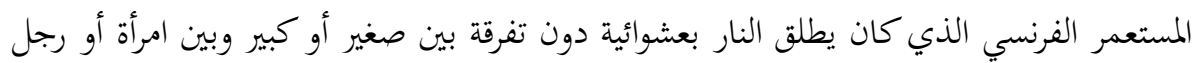
أثناء انطلاق المظاهرات المعارضة للتواجد الاستعماري في الجزائر والمطالبة بالاستقلال، وقد صور

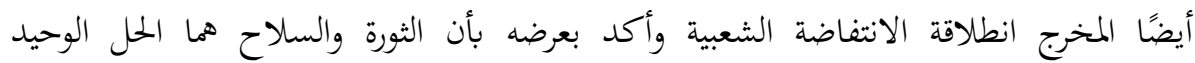
لاسترجاع السيادة الوطنية.

\section{التعقيب على الدراسات السابقة}

يلاحظ الباحث من خلال استعراضه للدراسات العلمية حول التحولات السياسية كما

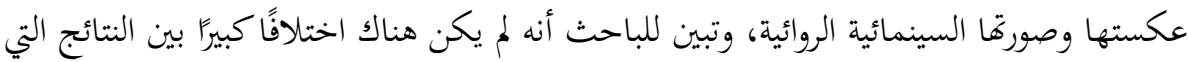

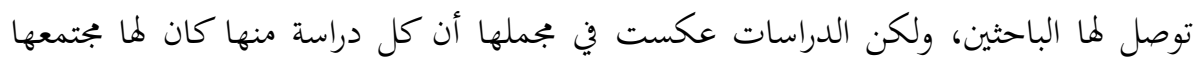

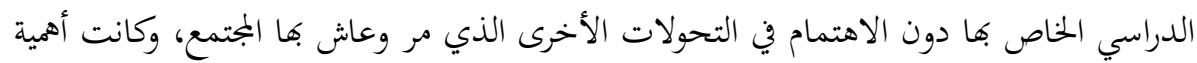
الدراسات التي عرضها الباحث تتمثل في الرصد لظاهرة التحولات السياسية والاجتماعية في الواقع 
العربي والغربي، ووصفت أيضًا الدراسات صورة النضال المجتمعي وصورة الاستعمار والحروب

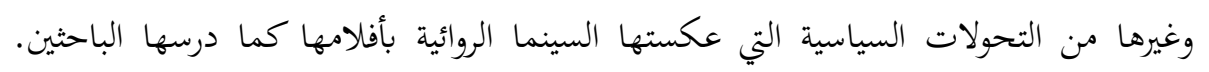
وتتشابه الدراسة الحالية مع دراسة الباحث عياد زويرة ودراسة مصطفى سحاري؛ أي أن الدراسة

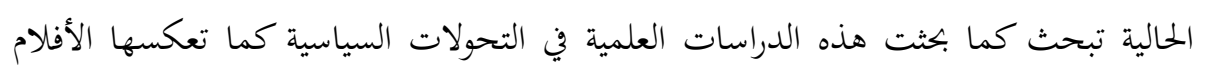

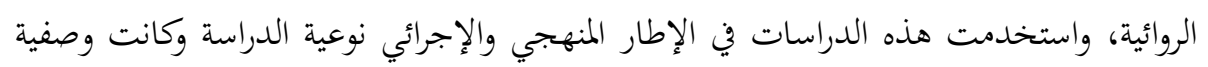

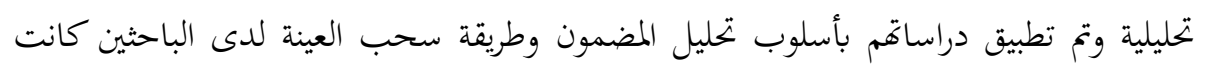

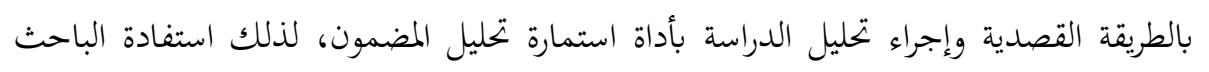

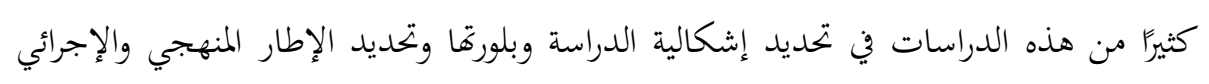
للدراسة وماهي النظرية العلمية المناسبة لدراسته أثناء التطبيق.

\section{الإطار النظري للدراسة}

\section{- ن ن - ن -}

اختلف العديد من الباحثين في تحديد الفترة الزمنية في إنشاء الاستشراق، لذلك يرى

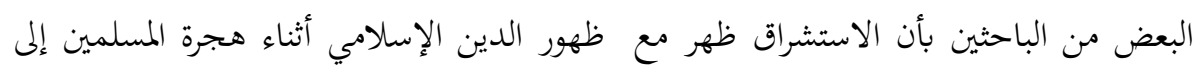

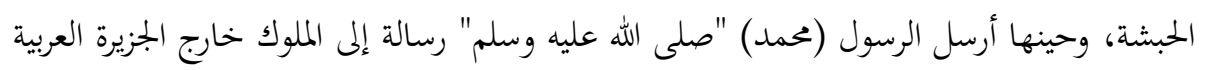

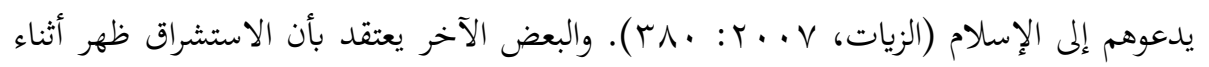

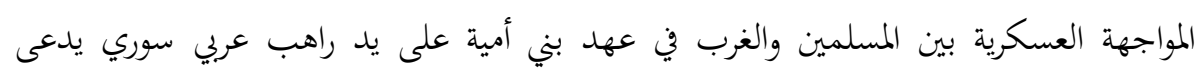

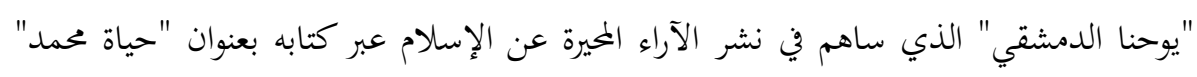

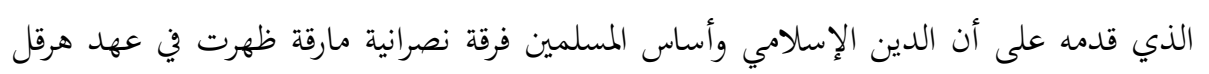

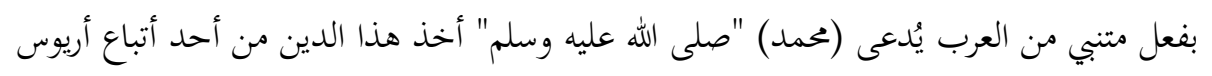

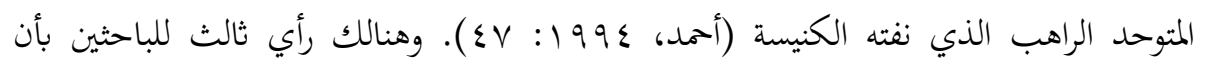

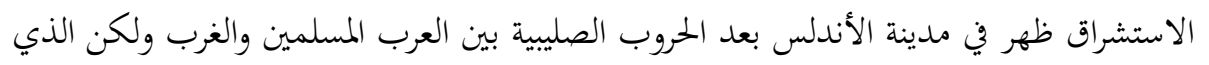

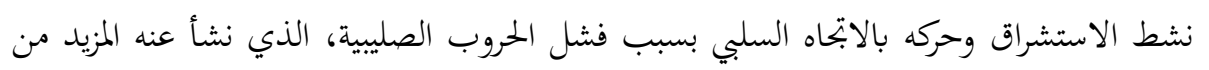
الاهتمام بالدين الإسلامي بدليل وصية القديس (لويس) ملك فرنسا وقائد الحملة الصليبية

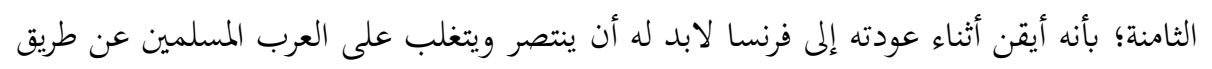


القوة الحربية وتحويل المعركة من ميادين السلاح إلى ميادين الأفكار والعقيدة ووجه العلماء الغربيين

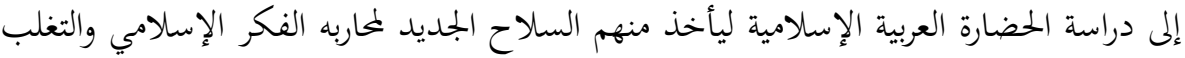

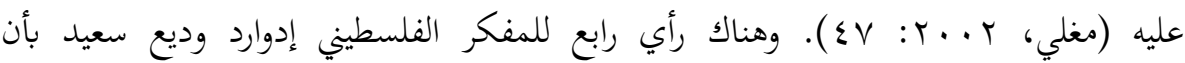

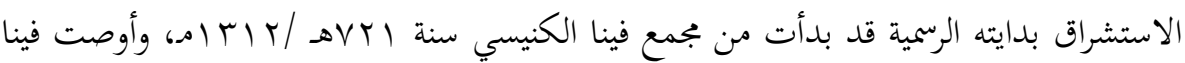

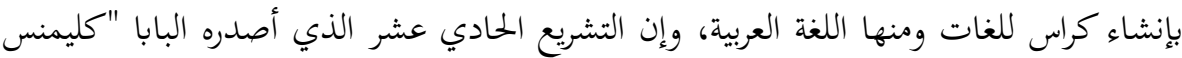
الخامس" بإنشاء كراس لتدريس اللغة العربية واللاتينية والعبرية والكلدانية (اللغة السريانية، واللغة الآرامية)، لجعلها لغات رئيسية في كافة الجامعات المركزية، وكان صاحب هذا الاقتراح الفيلسوف

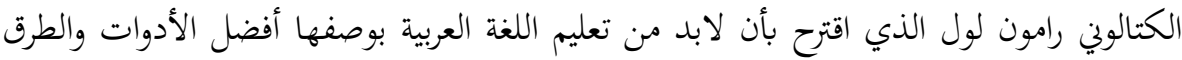

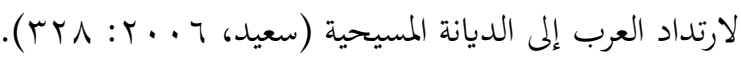

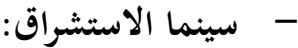

إن السينما الغربية وخاصةً سينما هوليود اختطفت وأسرت بلا منازع طريقة تفكير شعوب

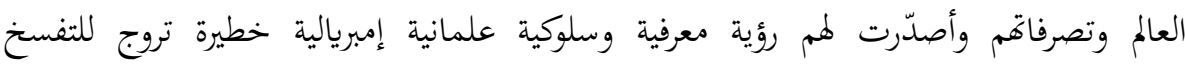
الأخلاقي. وحتى إذا أخذ الباحث بفرضية المخرجين الغربيين المزيفة القائلة بأن ما يشاهده المتلقين

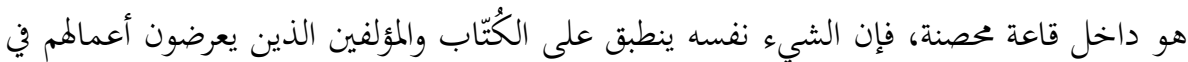

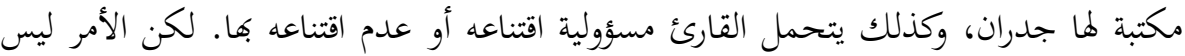
همذه البساطة؛ لأن الكاميرا بين يدي المخرج مثل القلم بين يدي الكاتب، والعمل الفني أو العمل

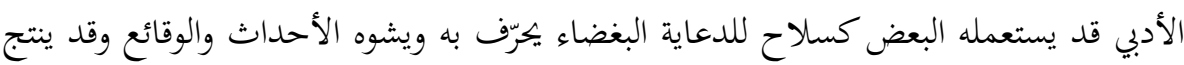
عن هذا التشويه هدم أقدس هيكل هرمي داخل أي مجتمع من المجتمعات.

وهنالك نموذج مثالي للباحث رافائيل باتاي في كتاب "العقل العربي"، الذي وجد له

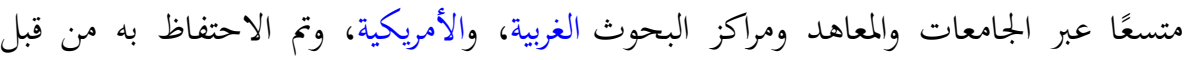

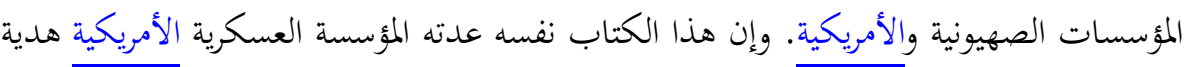
من السماء استعملته ولا تزال تستعمله كمصدر وكمرجع يستقي منه القادة الأمريكيين لمعرفة

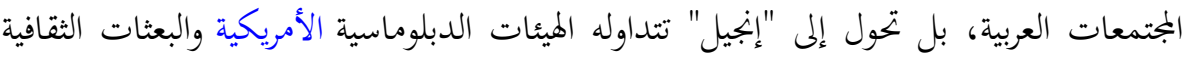
المختلفة العاملة في المنطقة العربية (كدواني، 1 ـ. ץ: rץ). ويرى الباحث بإن الحرب الإمبرياليّة 


\section{التحولات الاجتماعية والسياسية في الجزائر كما يعكسها الفيلم السينمائي الروائي....العدد الثالث والثلاثون}

التي شنتها الولايات المتحدة الأمريكية على العراق وأفغانستان والحرب الصهيو - نازية التي تريد أن

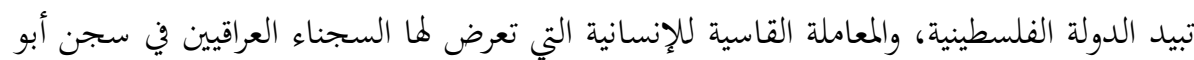
غريب وتعرض إليها سجناء غوانتانامو كما صورتا الأفلام السينمائية الوثائقية والروائية، وإن هذا ما هو إلا حصيلة عن الأفكار الاستشراقية السلبية.

\section{كيفية تطبيق نظرية الاستشراق في الدراسة}

إن الباحث اعتمد في تطبيق دراسته الحالية على نظرية الاستشراق، ويستخدم الباحث نظرية الاستشراق لتكون ردًا على المستشرقين السلبين الذي ينظرون إلى العرب بأغم لا يمتلكوا إنجازات وانتصارات على الغرب، ليؤكد بها الباحث عن الحجم الكبير للإنجازات والانتصارات

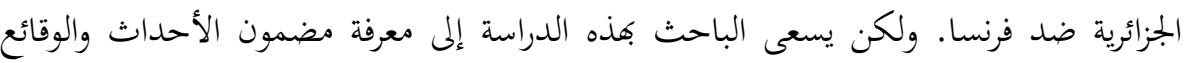
التاريخية في الرواية السينمائية لفيلم معركة الجزائر لما تحمله من شخصيات هامة وقضايا وظواهر

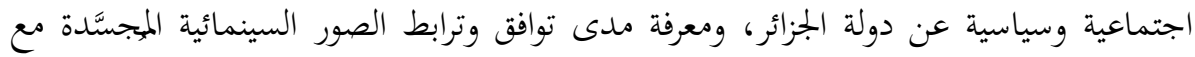

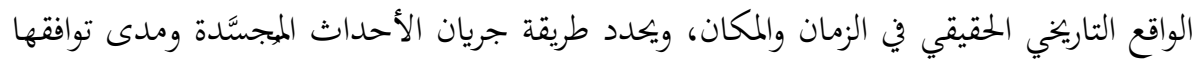
مع الحقبة الزمنية، ولهذه الأسباب تم تبني نظرية الاستشراق. التحليل الوصفيّ السيميولوجي لفيلم معركة الجزائر

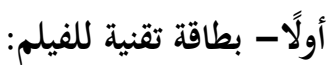

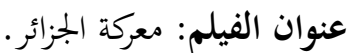
نوع الفيلم: روائي تاريخي. مخزج الفيلم: جيلو بونتيكورفو. مؤلف وكاتب الفيلم: ياسف سعدي وبونتكورفو وسوليناس. منتج الفيلم: أنطونيو موسو. شركة إنتاج الفيلم: شركة إيجور فيلم وشركة كباش سعد كباش فيلم. 
تصوير الفيلم: مارشيللو رجاني.

موسيقى الفيلم: إينيوموريكون.

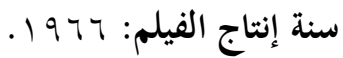

مدة الفيلم: بساعة ودقيقة واحدة.

بلد إنتاج الفيلم: إيطاليا والجزائر.

البلد المُجسَّد في رواية الفيلم: جمهورية الجزائرية الديمقراطية الشعبية.

\section{ثانيًا- بطاقة تقنية للمخرج:}

جيلو بونتيكورفو خخرج سينمائي إيطالي، ولد في 19 نوفمبر 1919 في مدينة بيزا

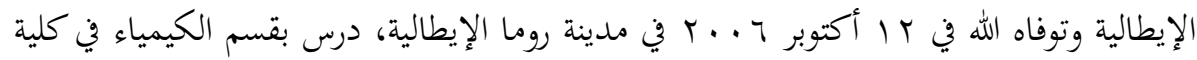
العلوم بجامعة بيزا، وبعد أن تخزج من الكيمياء قرر العمل في المجال الفني السينمائي وبدأ حياته لإنهاء

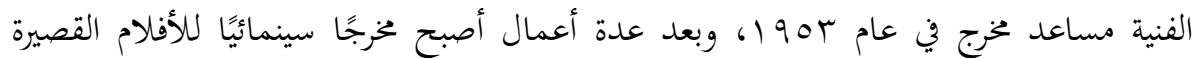
والطويلة، وكانت حصيلة أفلامه السينمائية التي أخرجها أربعة أفلام طويلة وفيلم واحد قصير.

ويعرض الباحث الأفلام السينمائية التي أخرجها المخرج الإيطالي جيلو بونتيكورفو بناءً

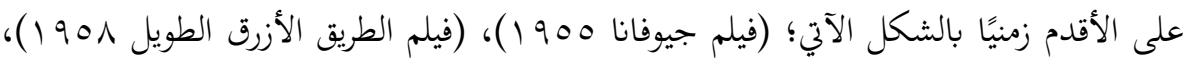

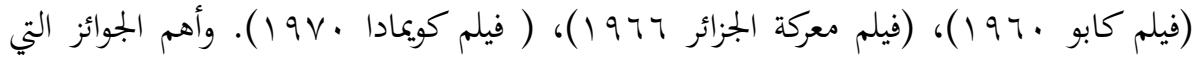

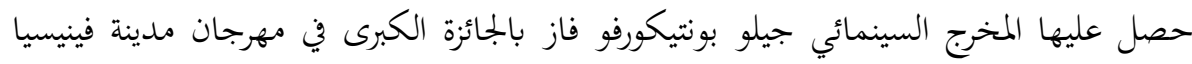

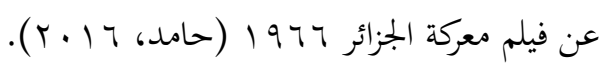

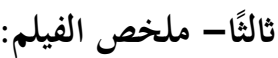

إن فيلم معركة الجزائر هو فيلم سينمائي روائي يعكس الواقع الجزائري قبل الاستقلال، وتم

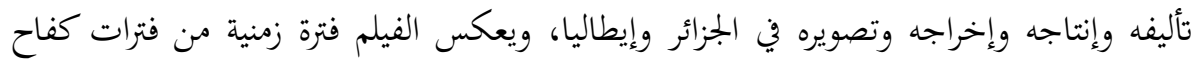

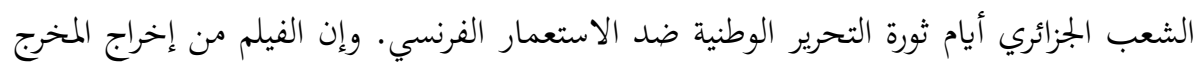


السينمائي الإيطالي جيلو بونتيكورفو وتأليف وسيناريو كاًا من ياسف سعدي وبونتكورفو

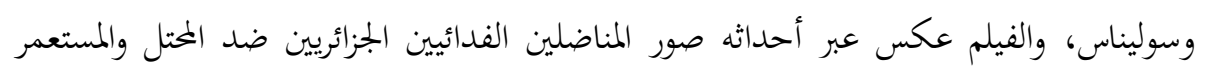
الفرنسي.

وتتحدث رواية الفيلم عن بطولة سكان حي القصبة ووقوفهم إلى جانب جبهة التحرير

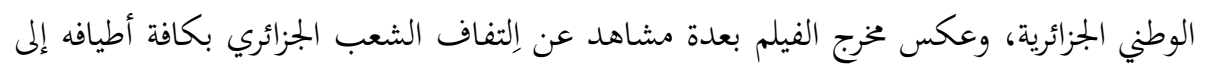

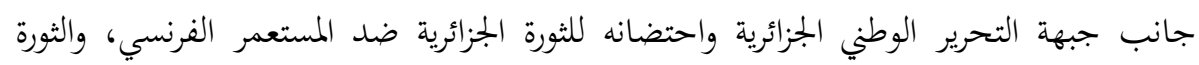

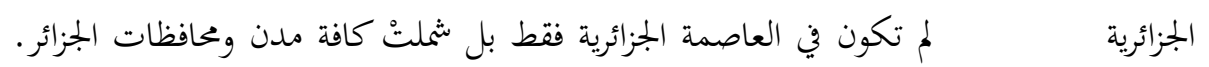

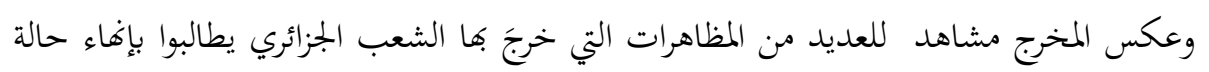
الاستعمار الفرنسي للجزائر وإعلان الاستقلال، دون أن تخيفهم العربات الحربية والأسلحة الثقيلة

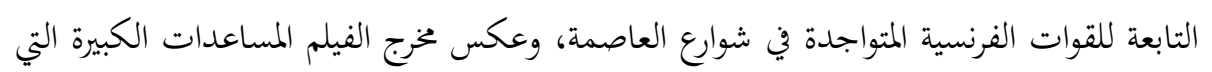

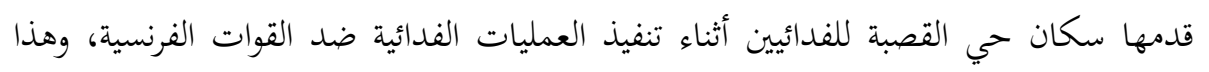

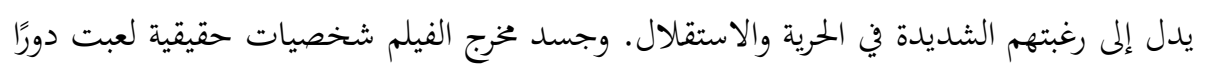

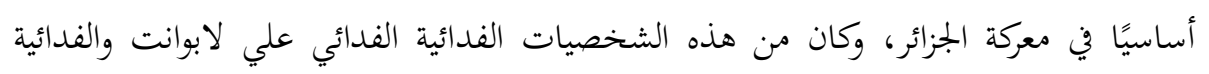

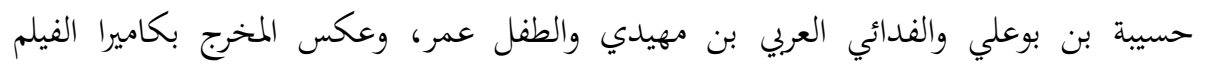

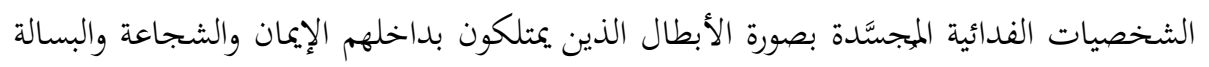

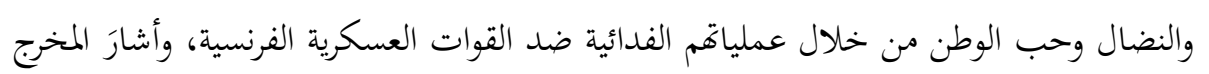

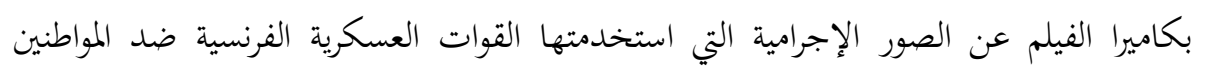

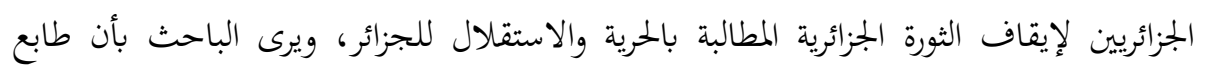
الواقعية الذي عكسه المخرج أعطى إضافة كبيرة في نجاح العمل الفني الروائي.

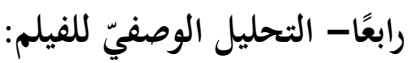

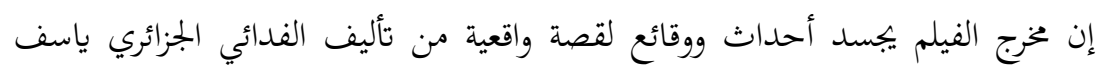

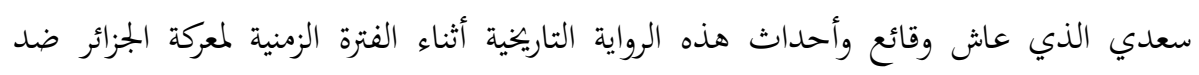

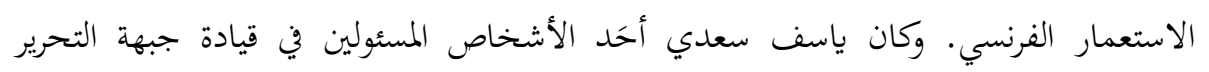

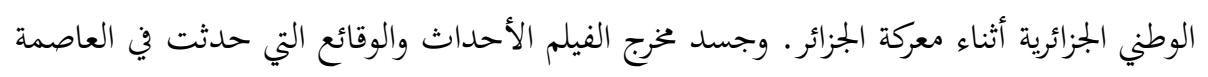


الجزائرية وخاصةً في حي القصبة أثناء حرب التحرير التي قادتا جبهة التحرير الوطني الجزائر ضد التدا

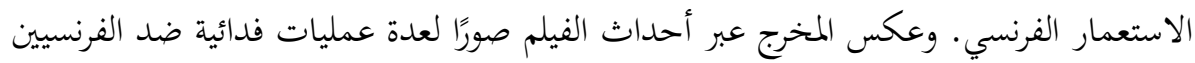

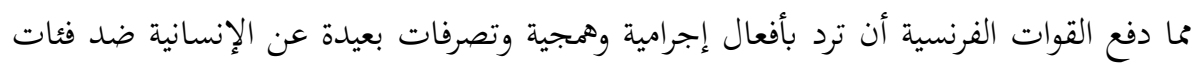
الشعب الجزائري.

وإن يخرج الفيلم جيلو بونتيكورفو الإيطالي الجنسية، اعتمد على مصادر علمية تاريخية

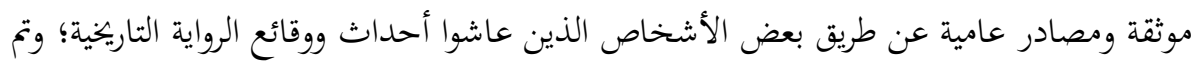

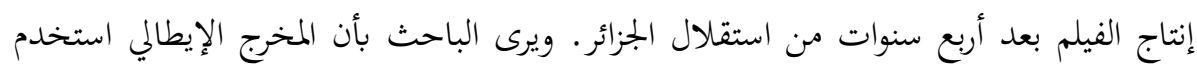

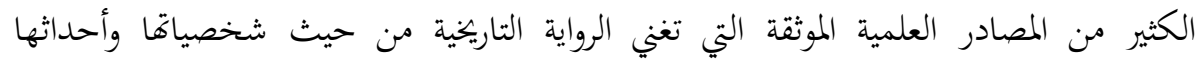

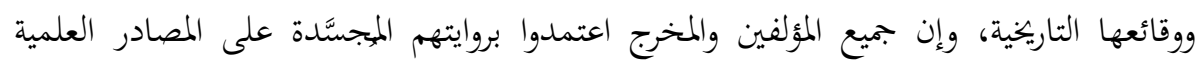

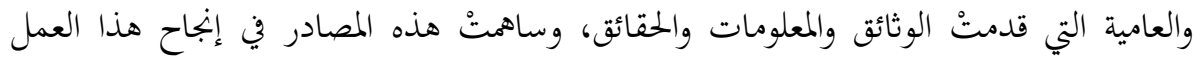
السينمائي.

\section{لقد تم تقسيم الفيلم الروائي التاريخي معركة الجزائر إلى ثلاثة محاور:}

1) حصار القوات الفرنسية لحي القصبة، واستشهاد الفدائي الشاب علي لابوانت والفدائية حسيبة بن بوعلي والفدائي محمود والطفل عمر.

r) زيادة الاعتقالات التعسفية للقوات الفرنسية لسكان حي القصبة، وإضراب الثمانية أيام،

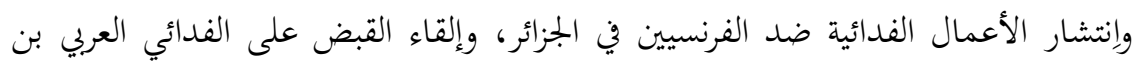
مهيدي.

r) أشكال وأساليب التعذيب السادية التي نفذها القوات العسكرية الفرنسية أثناء فترة معركة الجزائر لاستجواب الفدائيين الجزائريين.

وكتب المفكر المجري جورج لوكاش (Grorge Lulacs)، حول علاقة التاريخ بالفن،

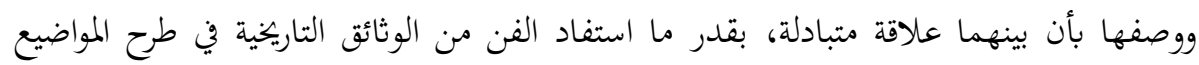

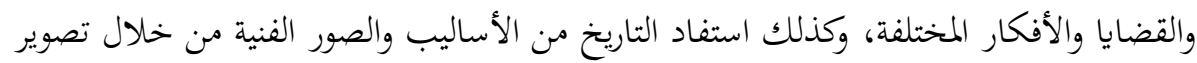

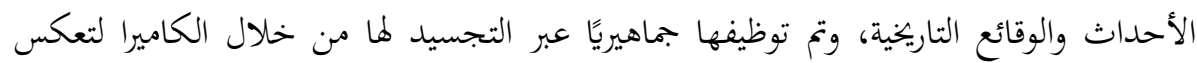


حاجات وهموم الإنسان في البجتمع، وأكد لوكاش على أهمية الربط بين الحاضر الماضي، من أجل

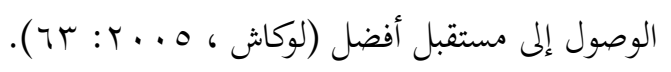

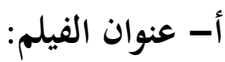

إن عنوان أي فيلم يصنع بحد ذاته لوحة كبيرة يصف بها معاني ووقائع الفيلم لكل متلقي

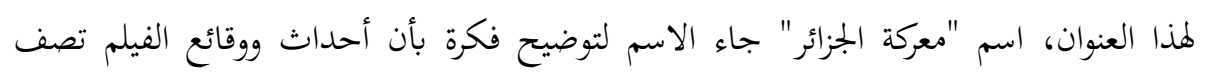

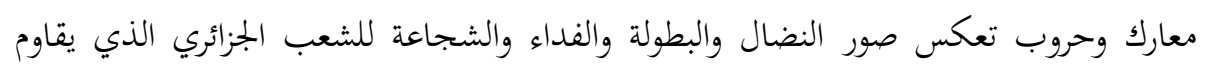
قوات الاستعمار الفرنسية.

العنوان معركة الجزائر: يُعد العنوان من أهم عناصر الجنيريك، ويرى الكاتب المسرحي

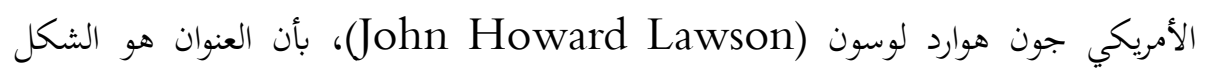

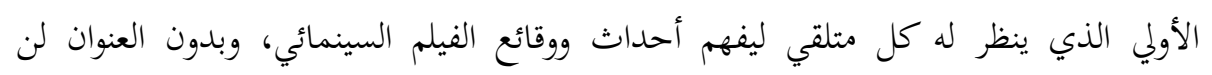

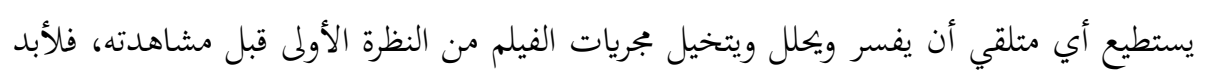

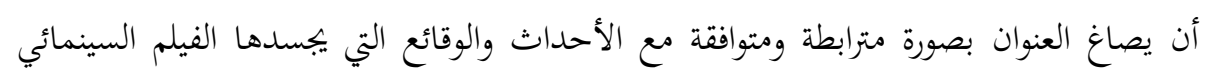

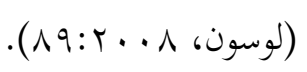

\section{ب- الموية الذاتية للشخصيات المُجسَّدة في فيلم معركة الجزائر:}

جسد المخرج جيلو بونتيكورفو أهم الشخصيات التاريخية في فيلم معركة الجزائر، وجسد

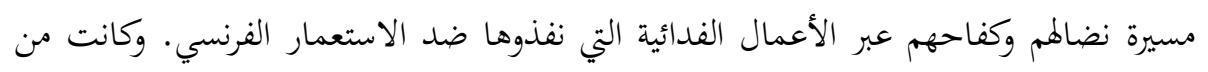

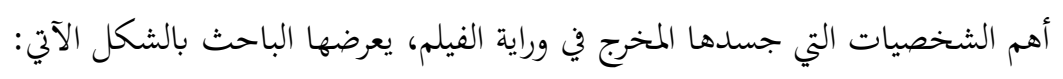

شخصية الفدائي الجزائري علي لابوانت، وجسد شخصيته الفنان الجزائري إبراهيم

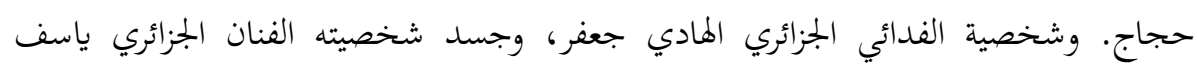
سعدي. وشخصية الجنرال الفرنسي ماثيو فيليب، وجسد شخصيته الفنان الفرنسي حيان مارتن.

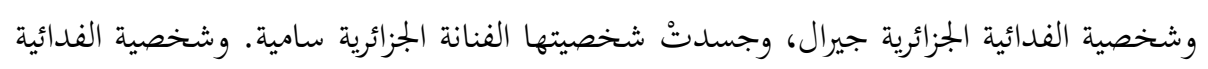

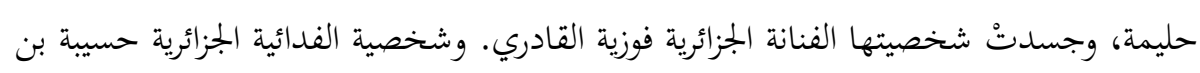

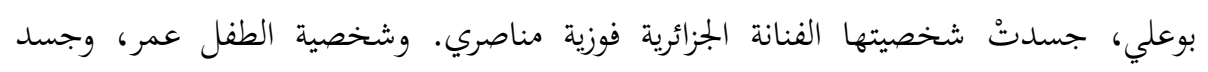


شخصيته الفنان الطفل الجزائري محمد بن كاسين. وشخصية الفدائي العربي بن مهيدي، وجسد شخصيته الفنان الجزائري زاكال. وشخصية الفدائي سي مراد، وجسد شخصيته الفنان الجزائري رويشد. وهذه كانت أهم الشخصيات التي جسدها المخرج في العمل السينمائي الروائي "معركة

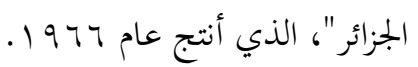

\section{ج- طبيعة الموضوعات التي تتناولها التحولات الاجتماعية والسياسية في فيلم معركة}

المقطع الأول: كانت بداية الفيلم يعكس بها المخرج عدة مشاهد قصيرة، عن التحولات

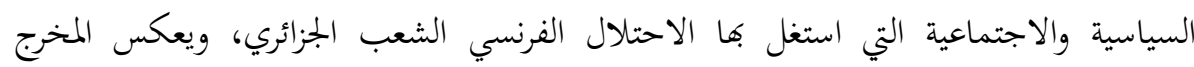

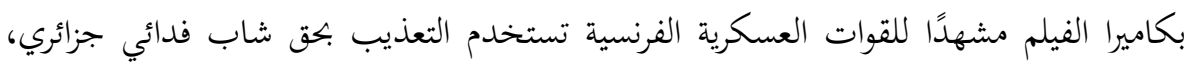
وكانت صورته شاحب اللون وهزيل الجسم؛ بسبب أساليب التعذيب الذي مارسته القوات

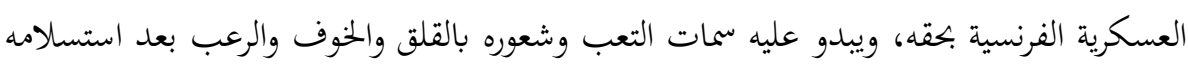

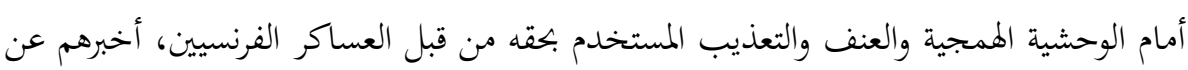

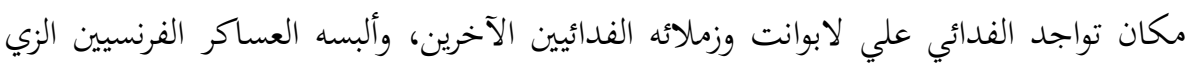

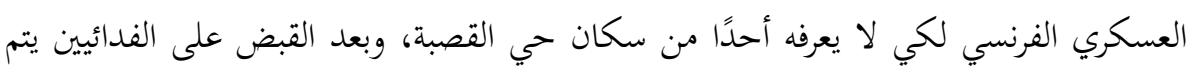

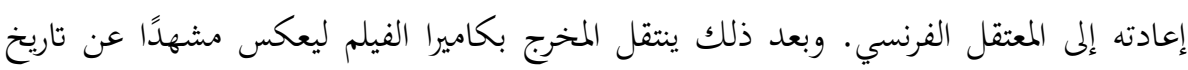

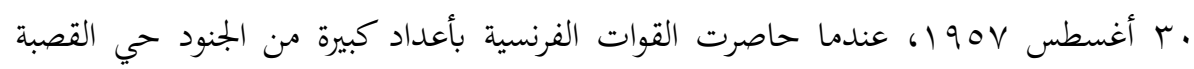

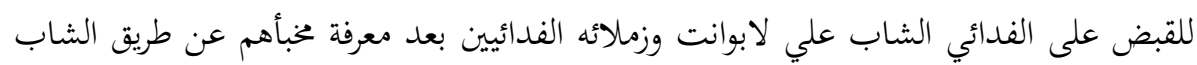

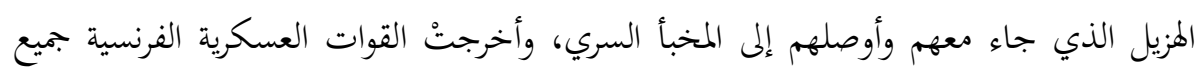

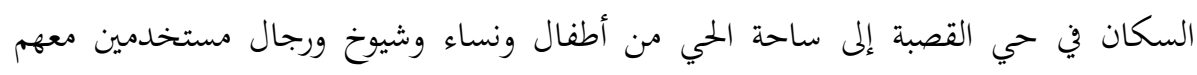

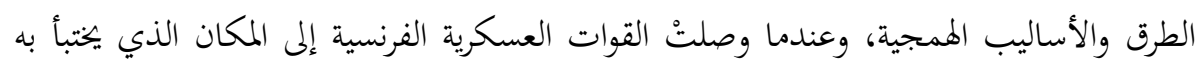

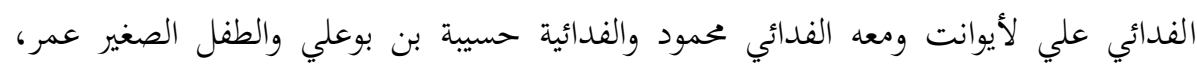

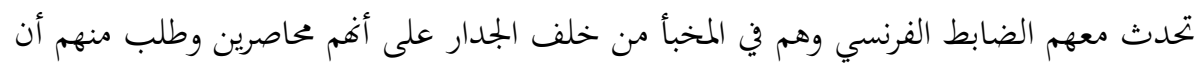

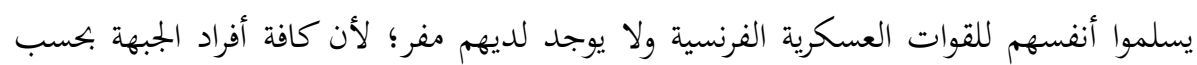

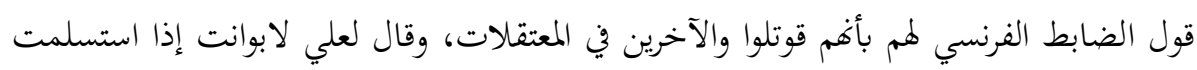

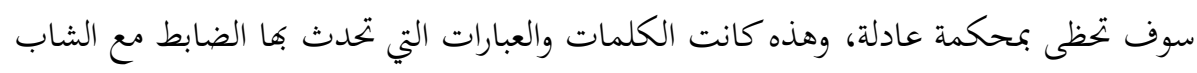

\section{$\Gamma \varepsilon \varepsilon$}


الفدائي علي لابوانت من خلف الجدار دون أي إجابة من الفدائي علي لابوانت. وانتقل بعدها المخرج بكاميرا الفيلم ليعكس العديد من المشاهد عبر تقنينه الفلان باك (Flache Back)

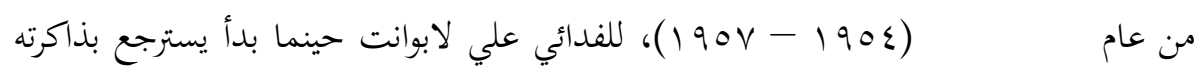

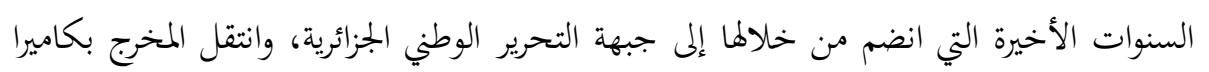

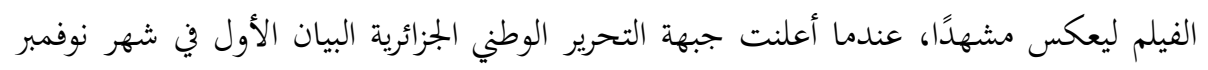

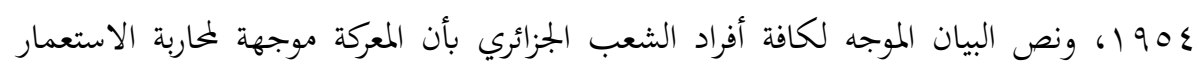

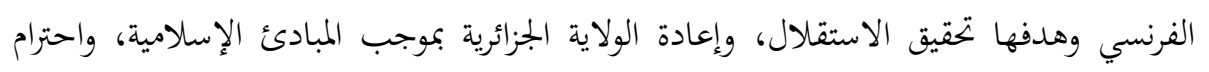

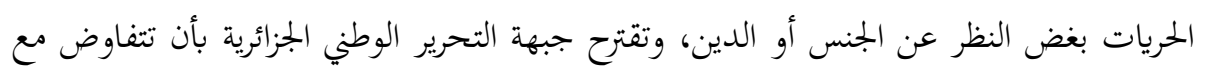

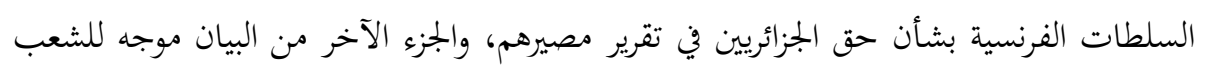

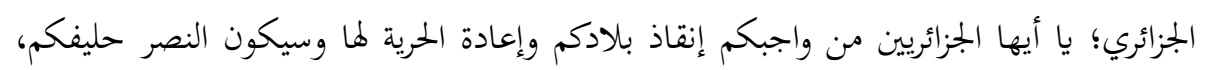

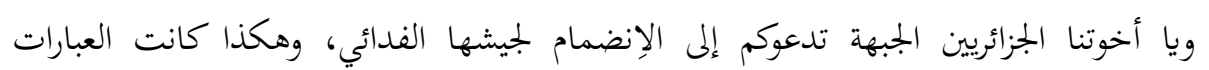

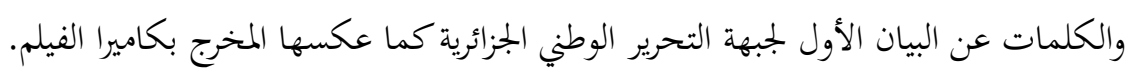

وثم انتقل المخرج بكاميرا الفيلم ليعكس مشهدًا آخرًا عبر تقنية الفلاث باك من ذاكرة

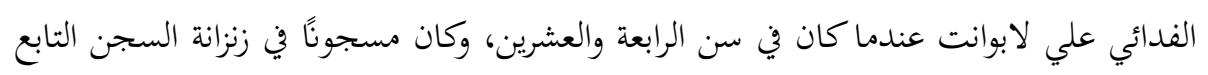

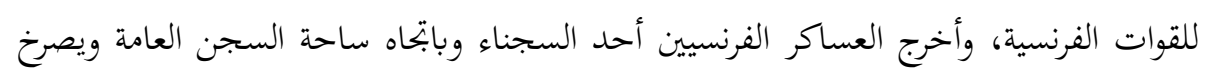

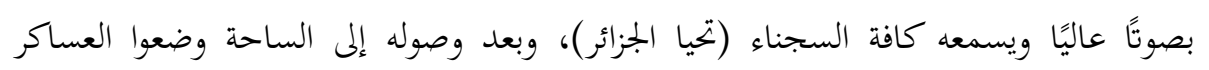

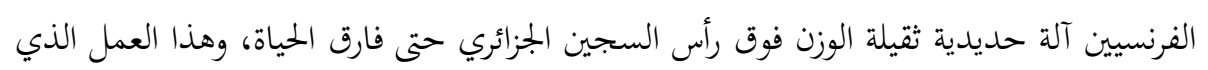

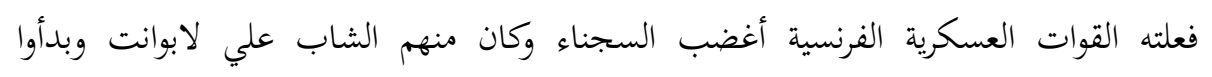

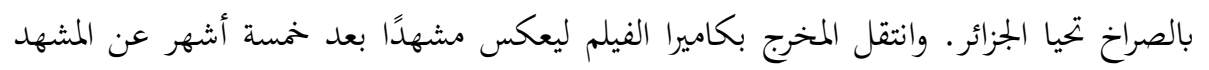

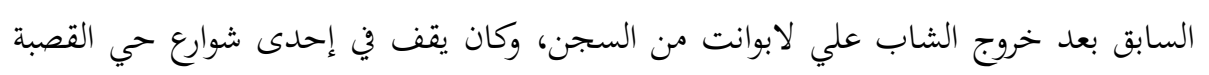

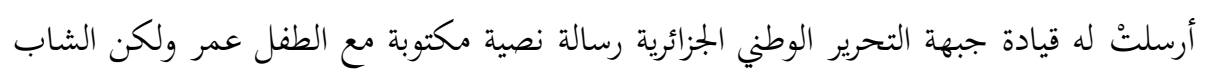

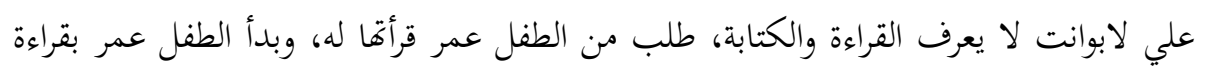

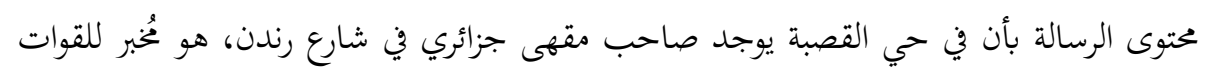

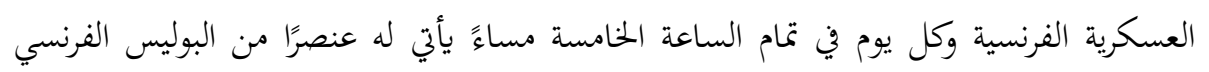

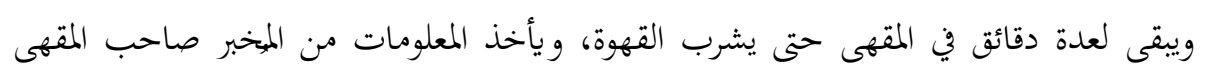


ومن بعدها يذهب، وتطلب قيادة الجبهة من علي لابوانت أن يقتل العنصر الفرنسي بجوار

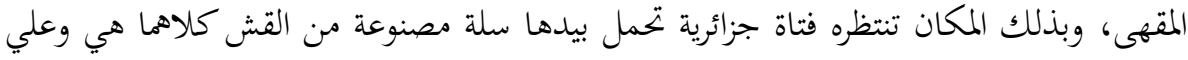

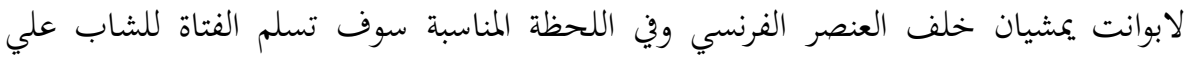

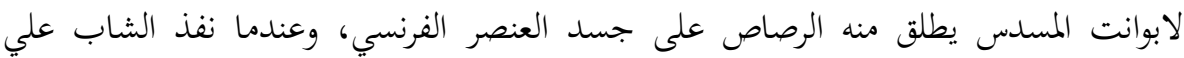
لابوانت العملية كان المسدس فارغًا من الرصاص، وهرب الشاب على علي لابسد الابوانت والفتاة ولم يتم

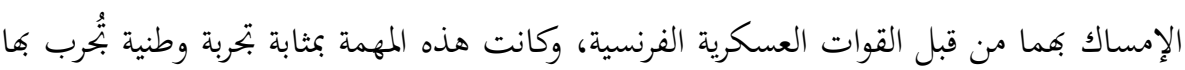
قيادة جبهة التحرير الوطني عناصرها الفدائين التي تختارهم وكان منهم الشاب علي لابوانت،

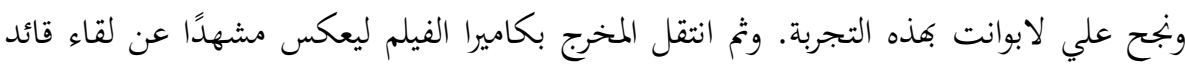

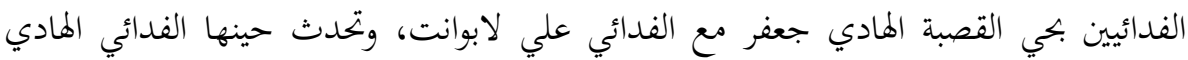
جعفر لعلي لابونت بأن تجربة قتل عنصر البوليس الفرنسي كانت لكي يتم التأكد بأنك يا علي لئي

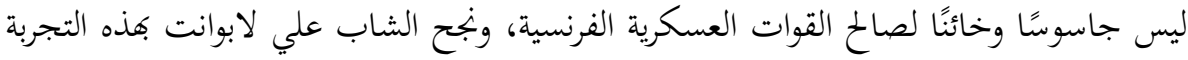

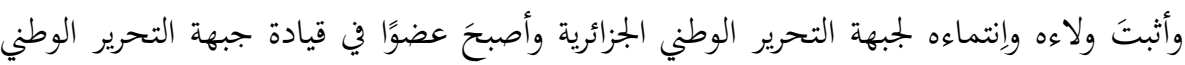
الجزائرية في حي القصبة.

المقطع الثاني: إِتْتَرَّ مخرج الفيلم في استخدام تقنية الفلاش باك من خلال هذا المقطع

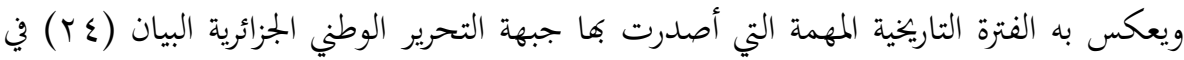

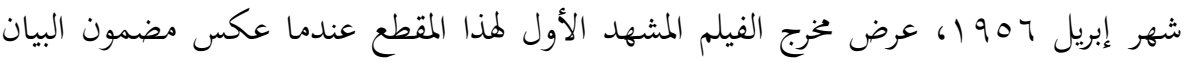

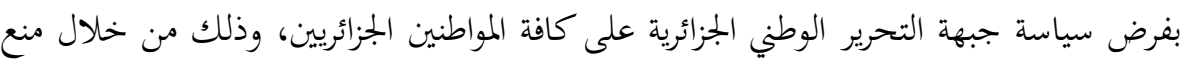

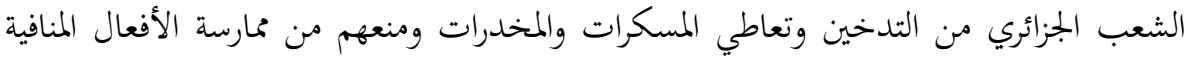

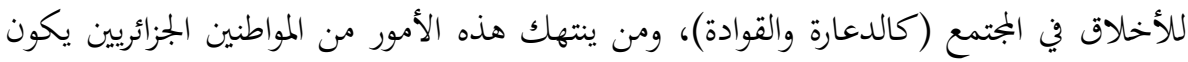
مصيره الموت، وهذا ما جاء بالبيان الذي نشرته جبهة التحرير الوطني بين كافة المواطنين الجزائريين

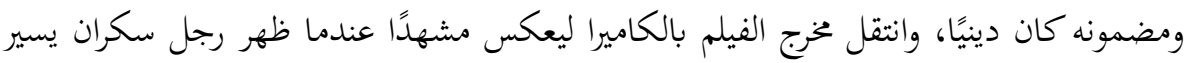

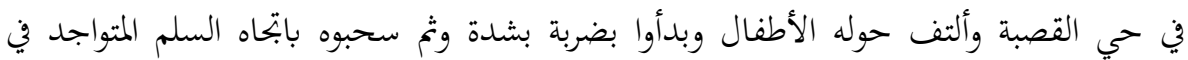

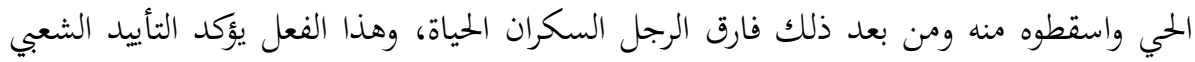
للمواطنين الجزائريين لقرارات جبهة التحرير الوطني الجزائرية. وثم انتقل المخرج بكاميرا الفيلم

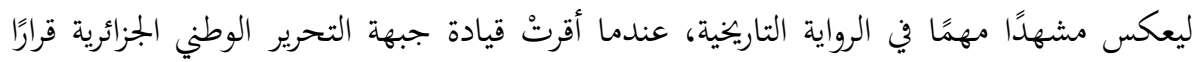


بأن يقوم الفدائي الشاب علي لابوانت بقتل الشاب الجزائري حسن البليدي؛ لأنه يساهم في

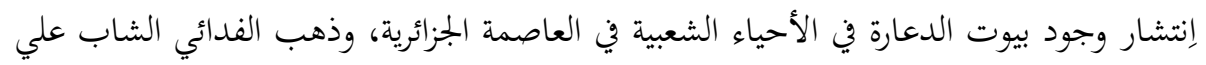

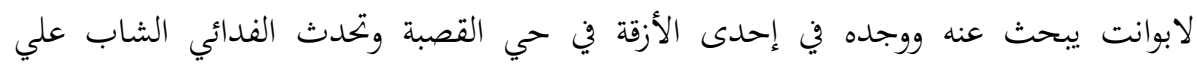

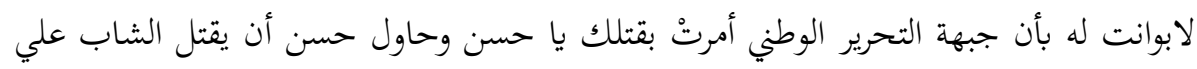

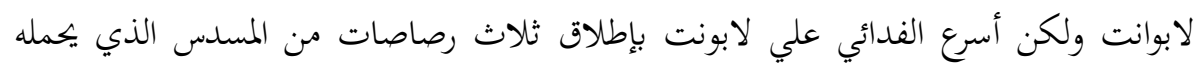

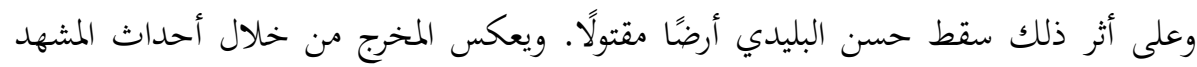
صورة التأييد الشعبي لأغلبية الجزائريين لقرارات جبهة التحريط التحرير الوطني الجزائرية.

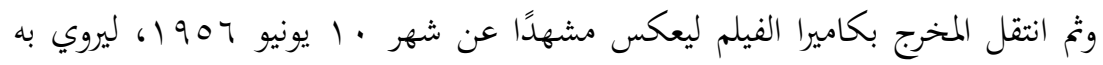
المخرج سيطرة جبهة التحرير الوطني الجزائرية على كافة أمور الحياة التي تخص المواطنين الجزائريين،

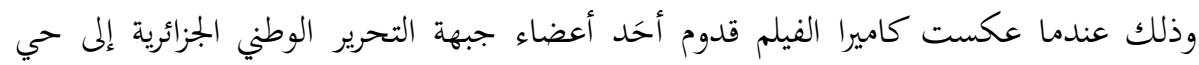

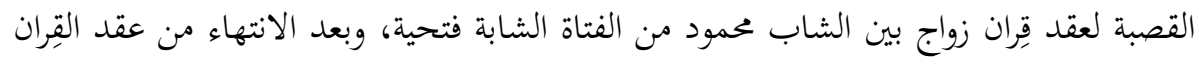

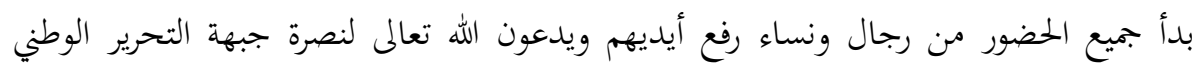

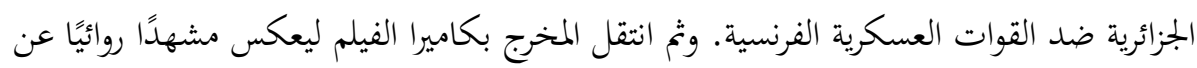

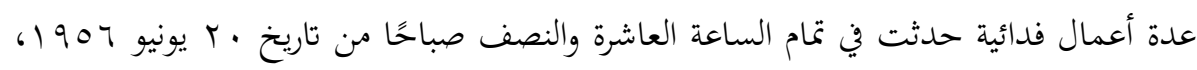

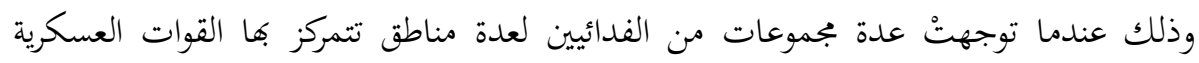
الفرنسية بأعمال تفجيرية، وبعد التفجيرات تم إطلاق الرصاص المتبادل بين الفدائيين الجزائريين

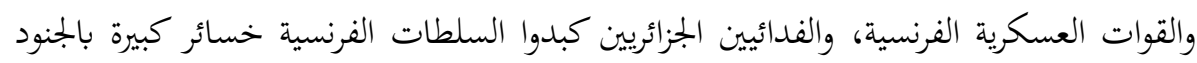

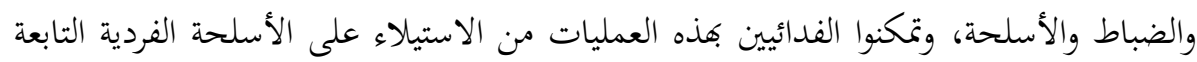

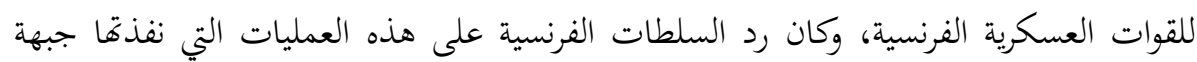

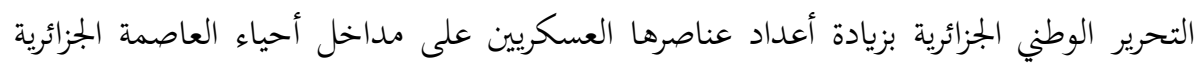

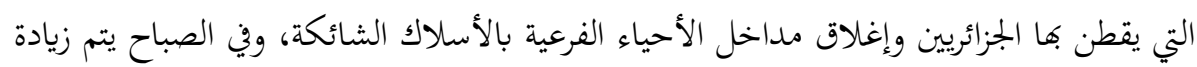

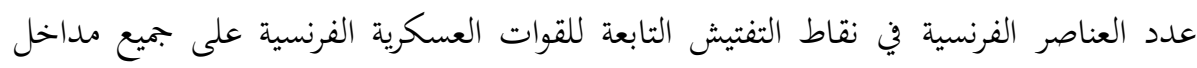

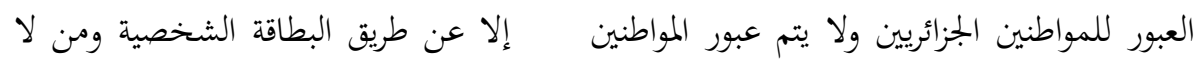

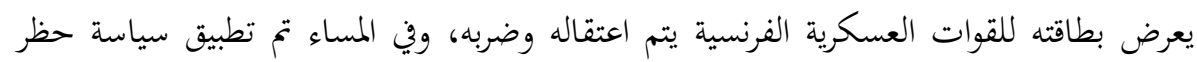

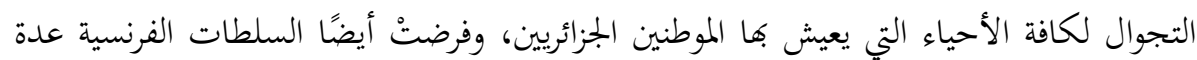


تدابير تعسفية منع بيع الأدوية والإسعافات الأولية الخاصة بالجروح والإصابات في الصيدليات باستثناء الأشخاص الذين يمتلكون تصريح من قبل السلطات الفرنسية، وعلى كافة المستشفيات

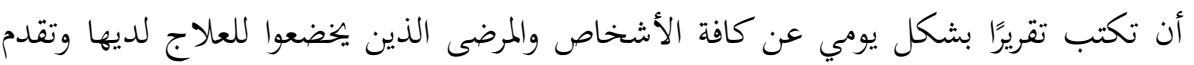

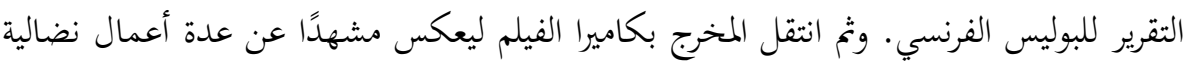

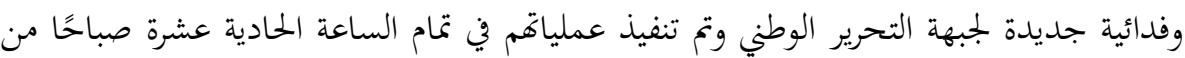
شهر · ب يوليو 1907، بعدة مناطق في العاصمة الجزائرية تتمركز بها القوات العسكرية الفرنسية

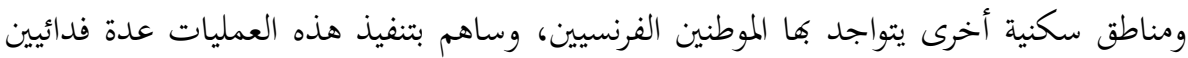
من النساء والشباب الجزائريين، وكان حجم الخسارة للسلطات الفرنسية من العساكر والموطنين

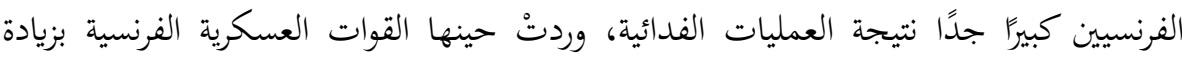
الاعتقالات التعسفية للموطنين الجزائريين وممارسة العنف بحقهم. وثم انتقل المخرج بكاميرا الفيلم

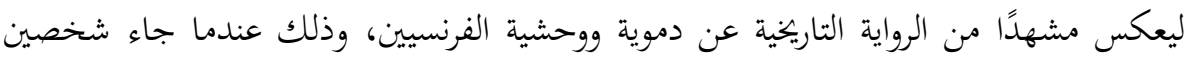

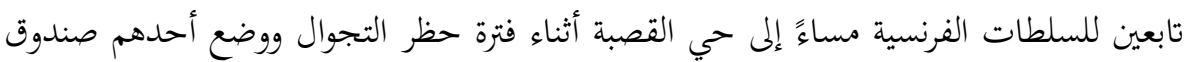
أمام الأبنية السكنية في الحي يوجد بداخل الصندوق قنبلة متفجرة، وبعد تفجير القنبلة سقطت التهاء

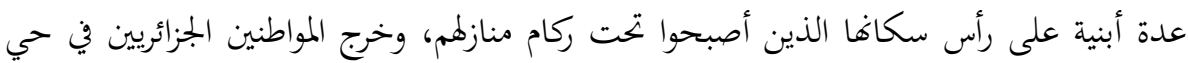

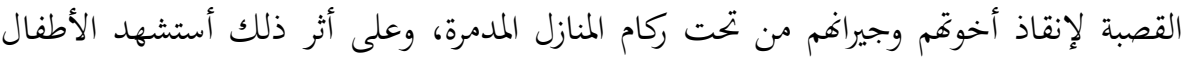

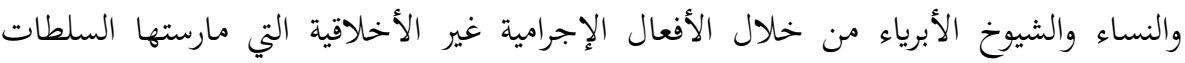

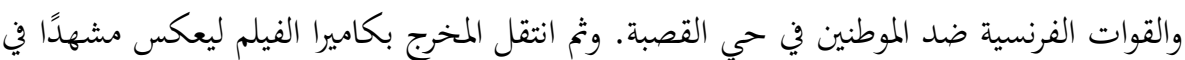

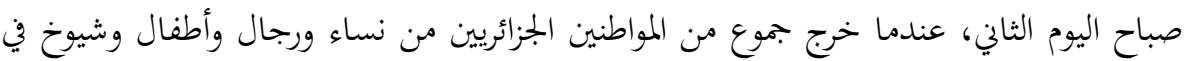

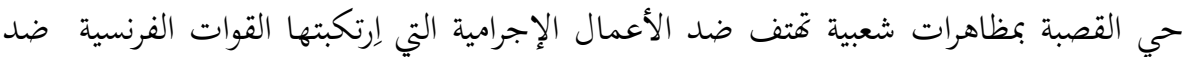

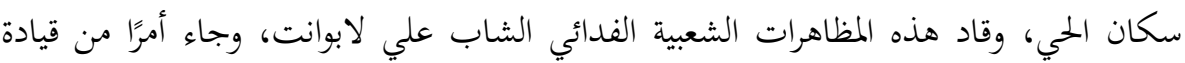

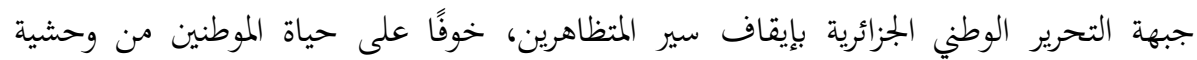

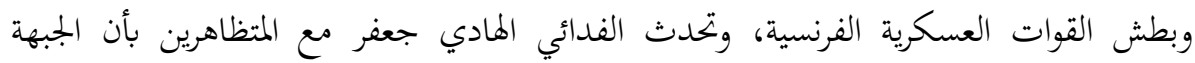
ستأخذ بالثأر للشهداء، وعاد جميع المتظاهرين الجزائريين إلى منازهم.

وثم انتقل المخرج بكاميرا الفيلم ليعكس مشهدًا لثلاثة أعمال فدائية ردًا على بجزرة حي

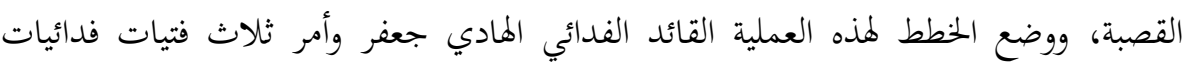


جزائريات أن ينفذوا العملية، وذلك من خلال إرتداء الفتيات لباسًا شبيهًا بلباس الفتيات الفرنسيات، وكل فتاة منهم تحمل حقيبة نسائية يوجد بداخل الحقيبة قنبلة متفجرة تنفجر القنبلة

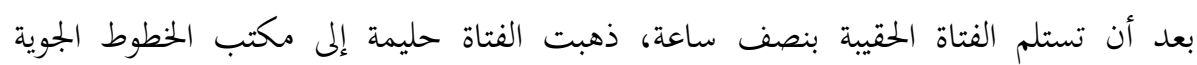

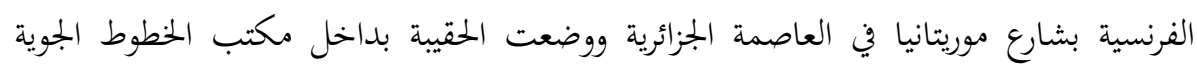

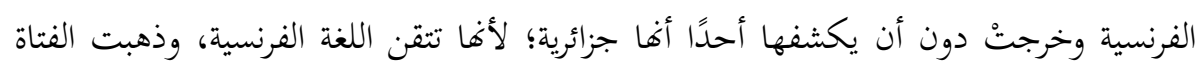

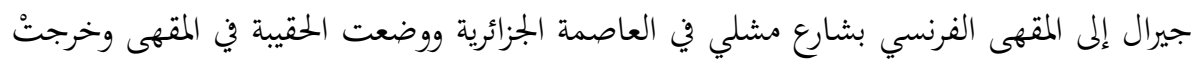

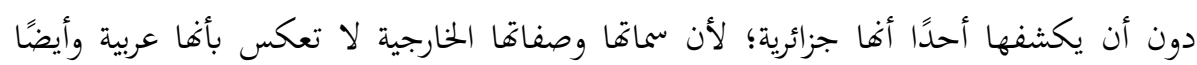

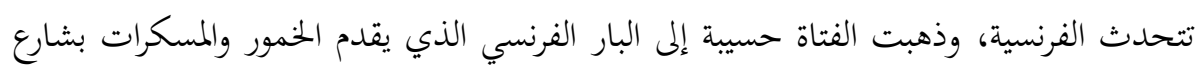

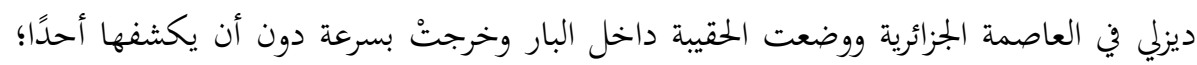

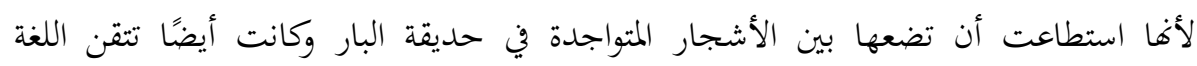

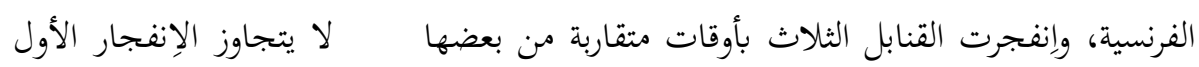

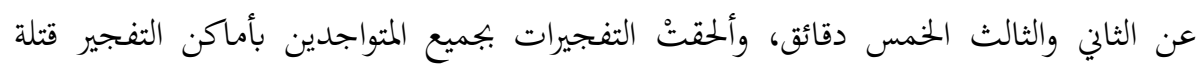

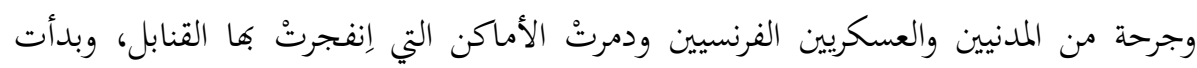

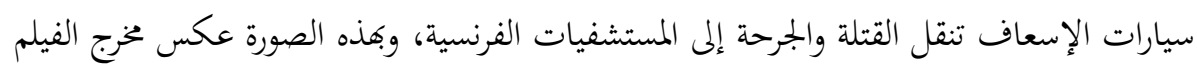

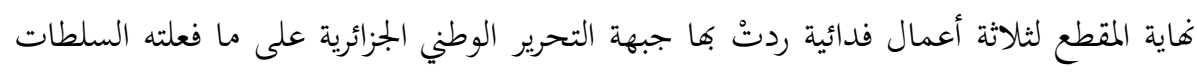
الفرنسية وقواتا العسكرية بحق الموطنين الجزائريين في حي القصبة.

المقطع الثالث: ويستمر مخرج الفيلم في استخدام تقنية الفلاث باك من خلال هذا المقطع

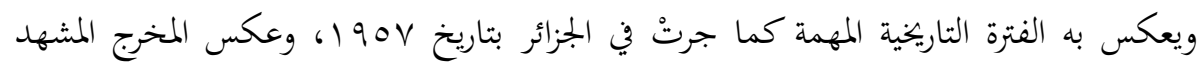

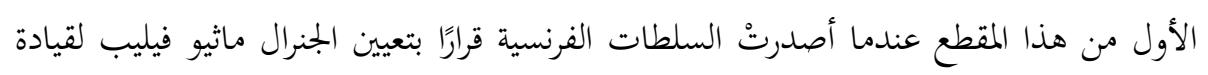

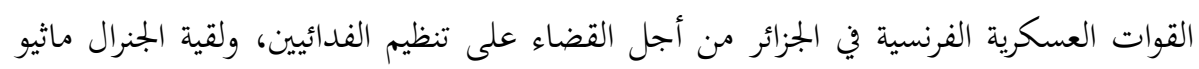

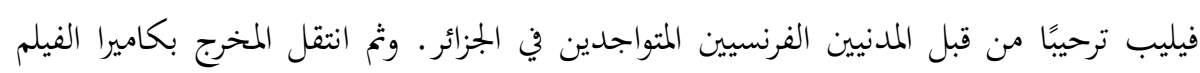

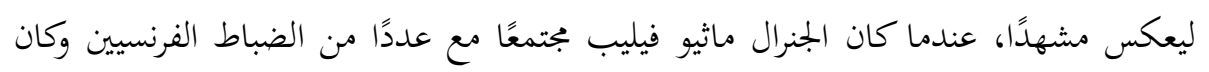

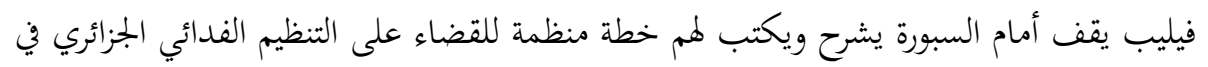

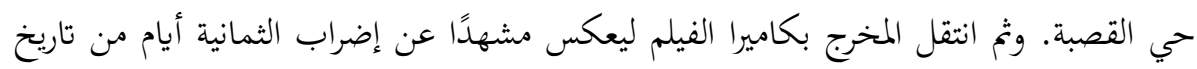

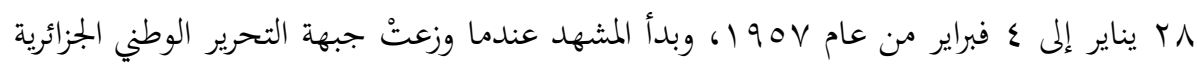


المنشورات إلى كافة المواطنين الجزائريين المثواجدين في الأسواق والمحلات التجارية في داخل العاصمة الجزائرية، ونشرت أيضًا الصحيفة الفرنسية لوموند عن إضراب الثمانية أيام للشعب

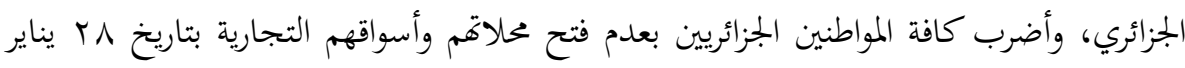
190V، وكان سبب الإضراب بسبب المعاملة السيئة والاعتقالات التعسفية التي تستخدمها

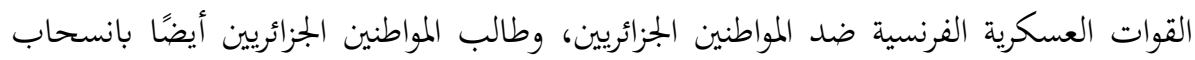

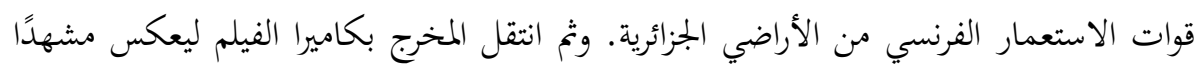

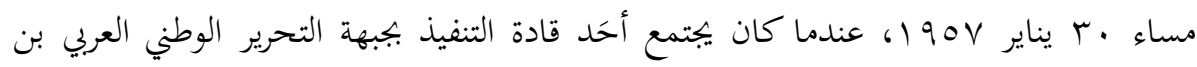
مهيدي مع قائد الفدائين بحي القصبة الهادي جعفر، وتحدث العربي بن مهيدي حول تقديم إنداء

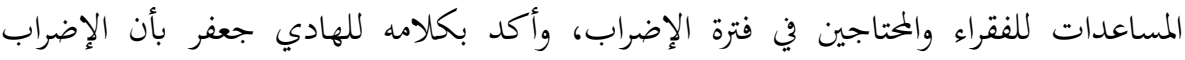

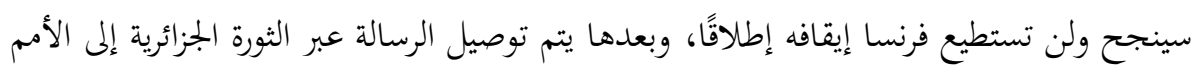

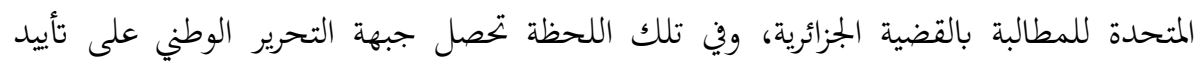

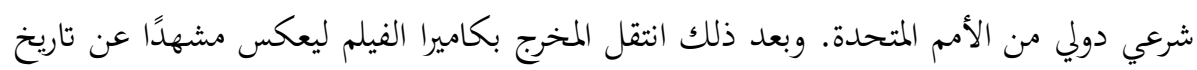
r فبراير 190V في اليوم السادس من الإضراب، عندما بدأت القوات العسكرية الفرنسية بقيادة

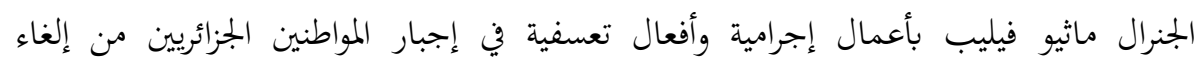

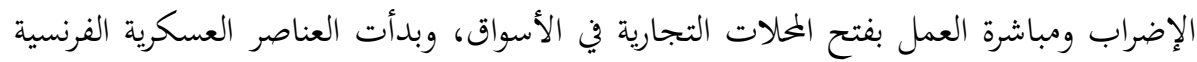

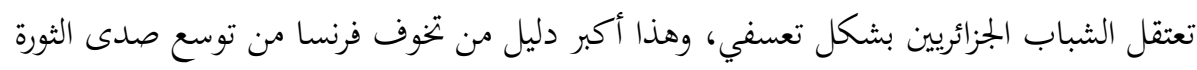

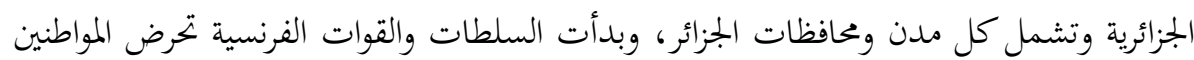

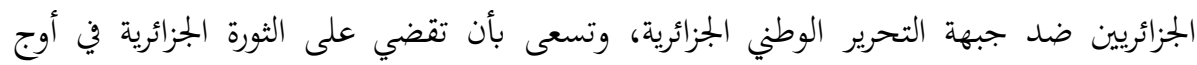

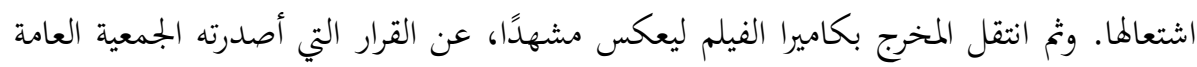

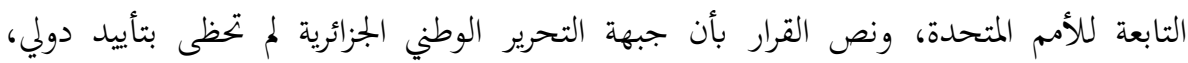

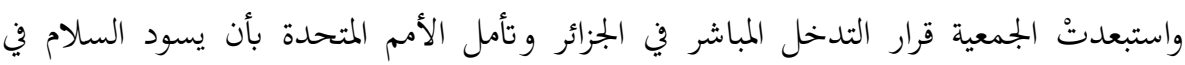

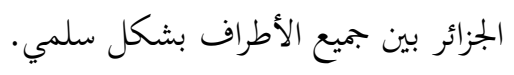

وثم انتقل المخرج بكاميرا الفيلم ليعكس مشهدًا، عندما اجتمع الجنرال ماثيو فيليب

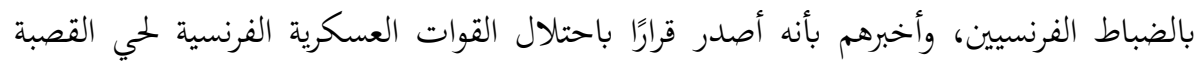

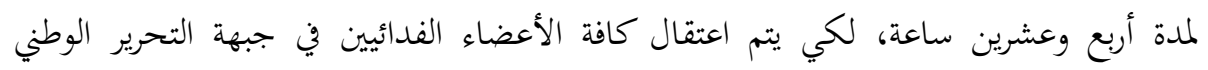


الجزائرية والمكتب التنفيذي للجبهة؛ لأن جميعهم يتمركزوا في حي القصبة، وأكمل الجنرال ماثيو

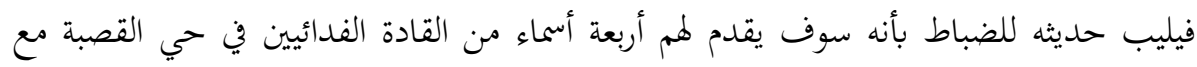
صورهم الشخصية وحصل عليها من سجلات الشرطة الفرنسية، وأول الأسماء سي مراد والثاني

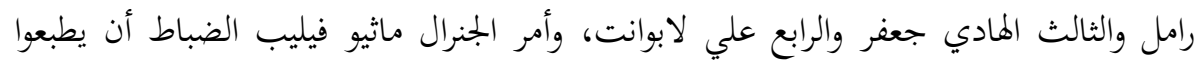

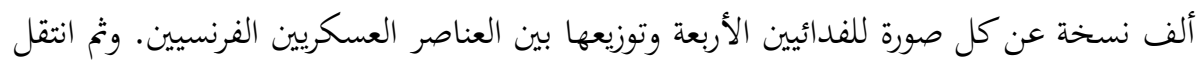

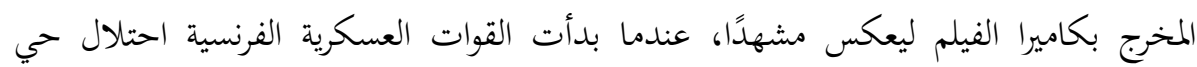

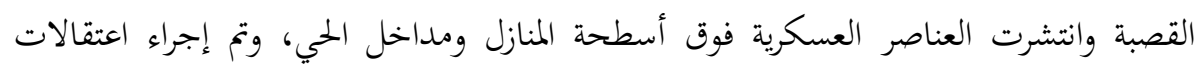

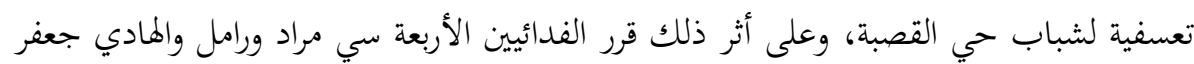

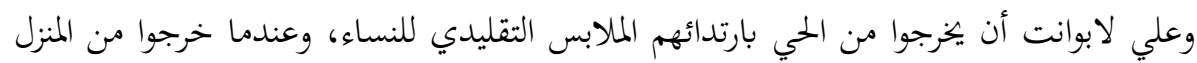

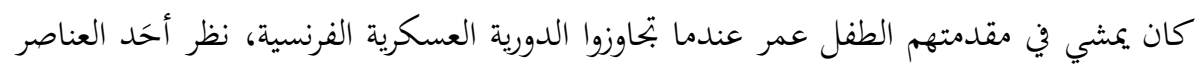

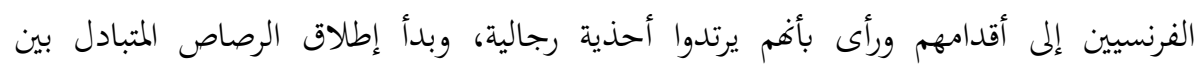
الفدائيين الأربعة والدورية العسكرية الفرنسية في داخل أزقة شوارع حي القصبة، وتفرقوا الفدائيين

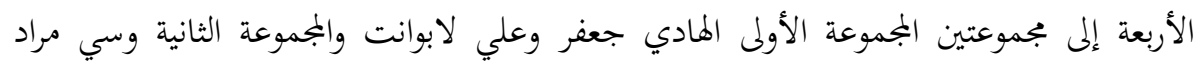

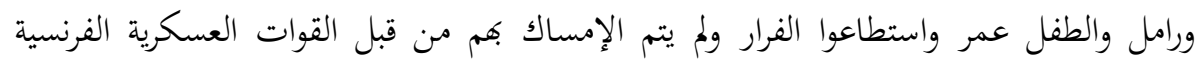

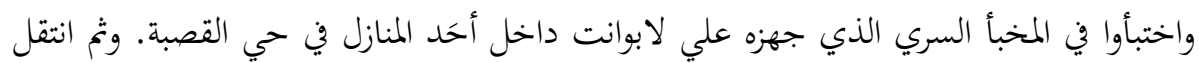

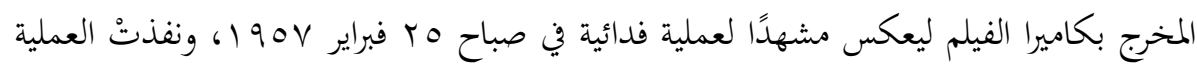

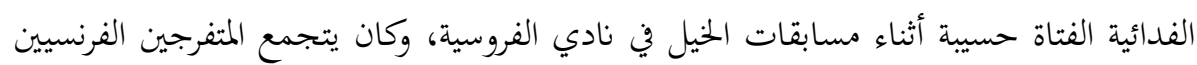

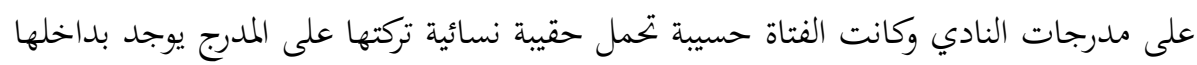

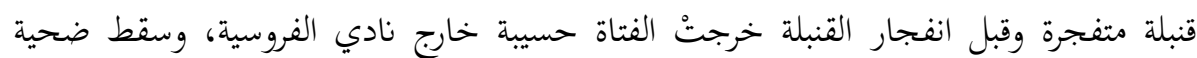

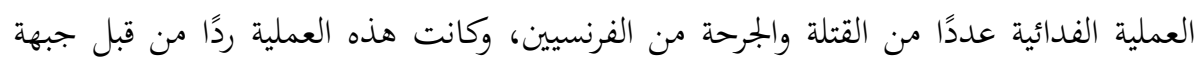

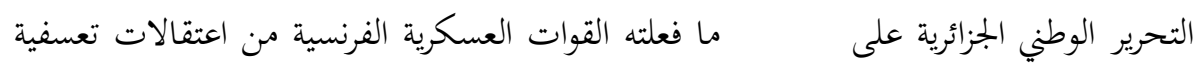
وأعمال عنف بحق المواطنين الجزائيين.

المقطع الرابع: ويستمر مخرج الفيلم في استخدام تقنية الفلاش باك من خلال عدة

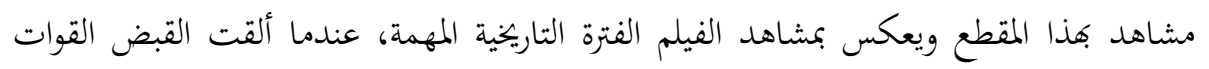

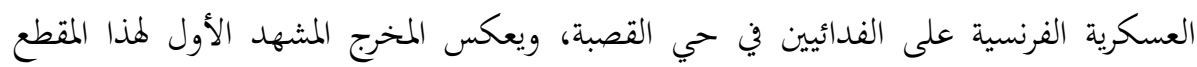


بتجسد وقائع وأحداث بتاريخ عارس مارس 190V، عندما ألقت القبض القوات العسكرية

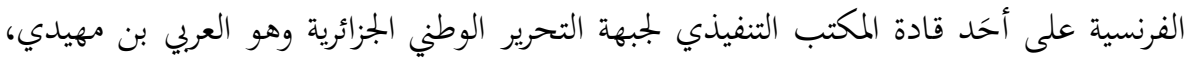
وعقد الجنرال ماثيو فيليب بمكتبه مؤتمرًا صحفيًا بحضور المعتقل العربي بن مهيدي يتحدث للصحفيين عن كيفية اعتقاله من قبل القوات الفرنسية، ووجه بعض الصحفيين الأسئلة للفدائي

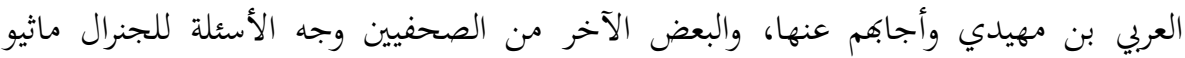

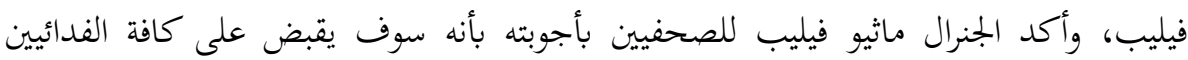

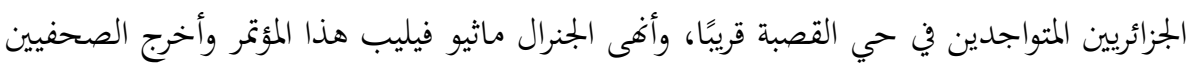

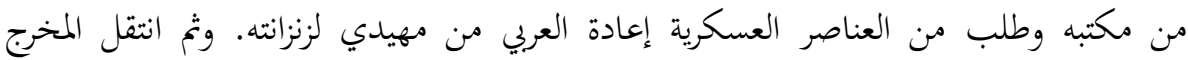

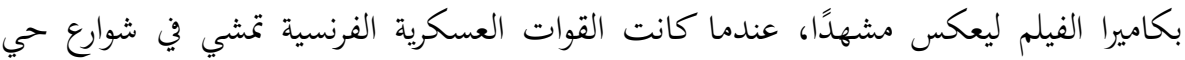

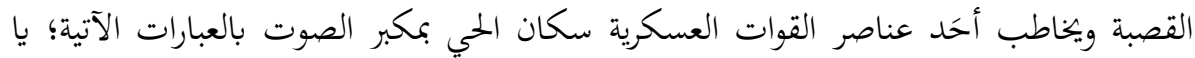

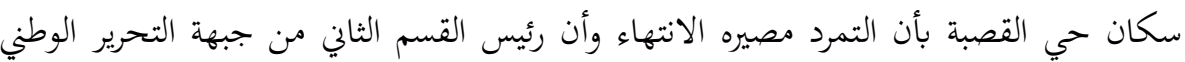

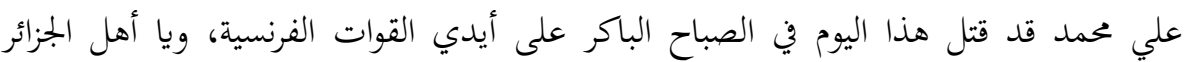

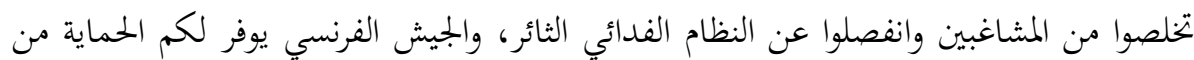

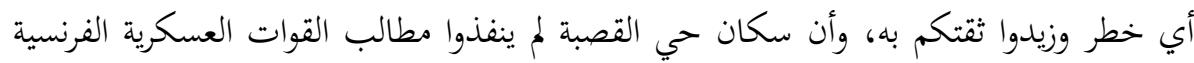

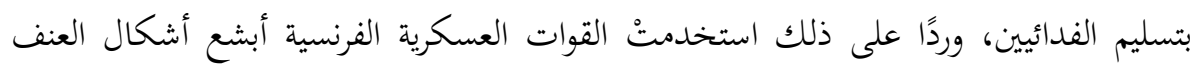

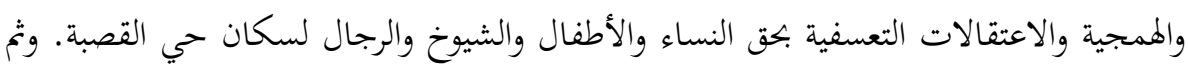
انتقل المخرج بكاميرا الفيلم ليعكس مشهدًا، عندما عقد الجنرال ماثيو فيليب مؤتمرًا صحفيًا

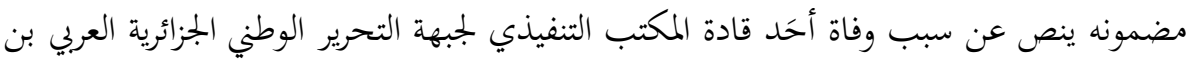

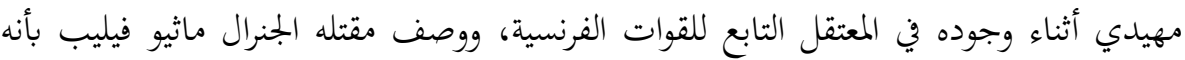

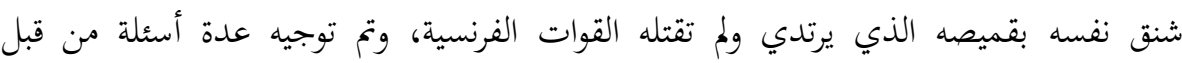
الصحفيين للجنرال الفرنسي عن صور التعذيب والعنف التي تستخدمها القوات العسكرية

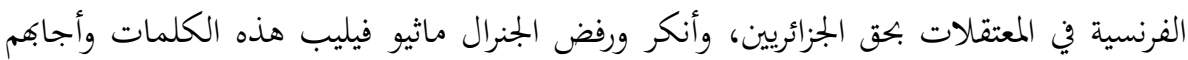

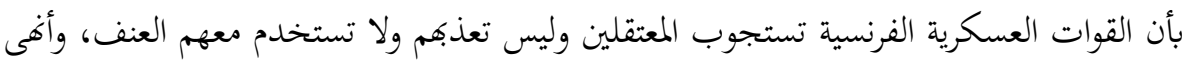
الجنرال ماثيو فيليب المؤتمر الصحفي وأخرج الصحفيين من مكتبه. وثم انتقل المخرج بكاميرا الفيلم

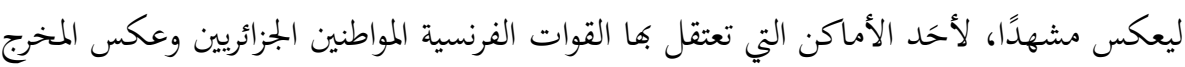
هذا المشهد صور التعذيب بحق المعتقلين الجزائريين، وكانت صور التعذيب حتى الموت من خلال 
استخدام العساكر والضباط الفرنسيين طرق ووسائل التعذيب بصورة همجية وسادية كالتعذيب

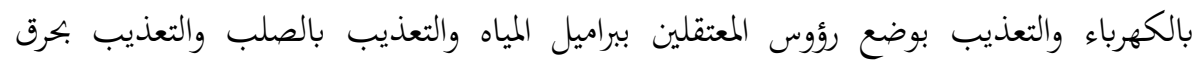

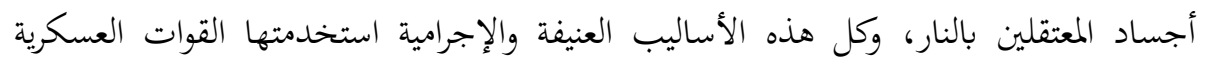
الفرنسية بحق المعتقلين الجزائريين كما عكسها وجسدها مخرج الفيلم عبر الرواية التاريخية. وثم انتقل

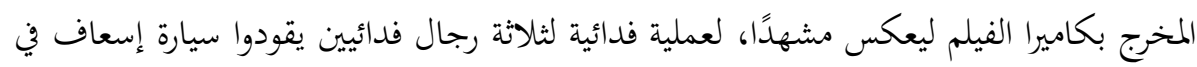

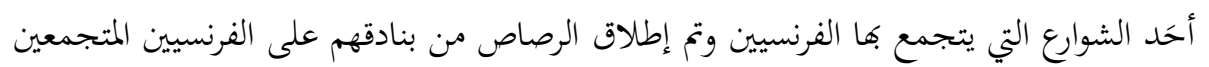

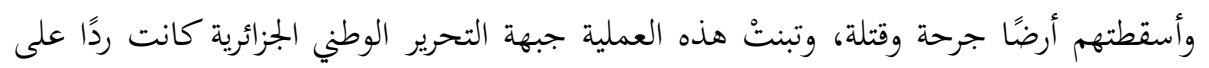
القوات العسكرية الفرنسية؛ بسبب استخدامهم التعذيب والعنف بحق المواطنين الجزائريين.

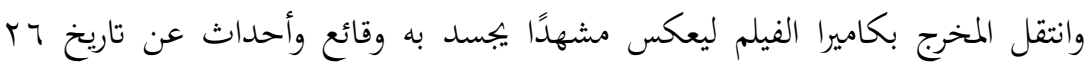

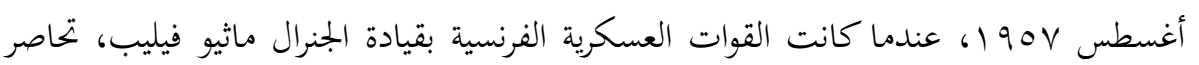

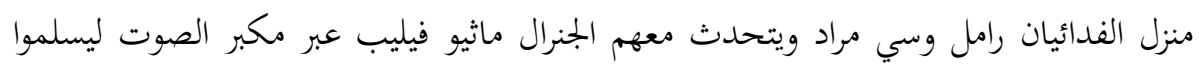

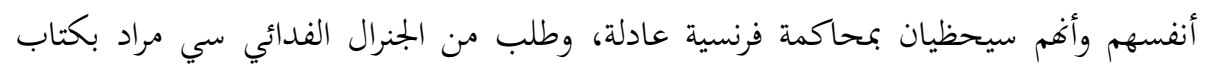

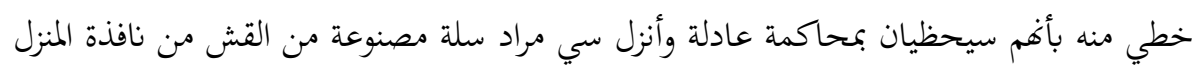
ليضع بها الجنرال الكتاب الخطي وكان يوجد في السلة قنبلة مؤقته تنفجر أثناء أنزال السلة

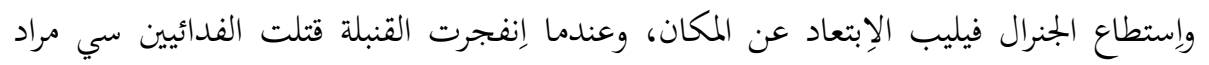

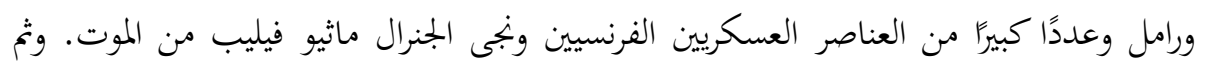

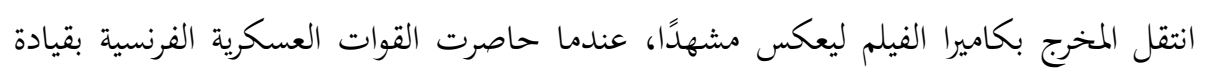

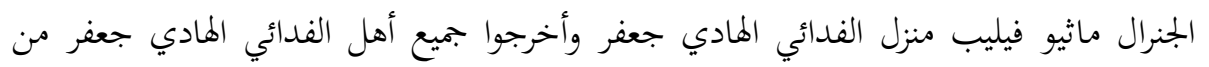

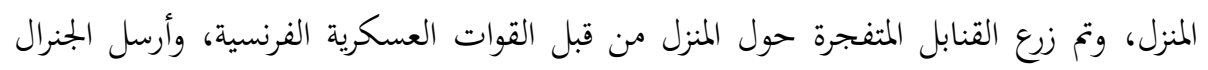

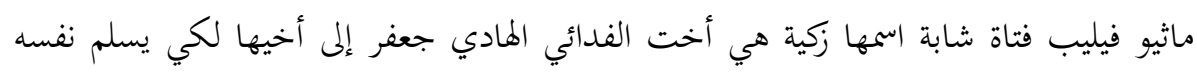

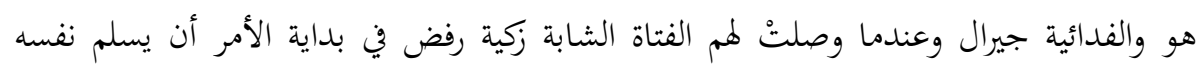
وفكر قليلًا أن يحافظ على منزل أهله الفقراء ويحافظ على حياة الفتاة جيرال وحياة أسرته وعائلته

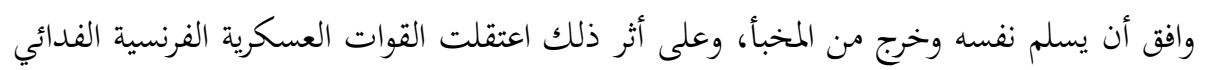
الهادي جعفر والفتاة الفدائية جيرال، وتحدث الجنرال ماثيو فيليب لهم بأن اللعبة إنتهت، وقال وقال له له

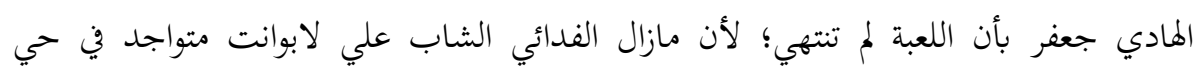


القصبة. وثم انتقل المخرج بكاميرا الفيلم ليعكس مشهدًا بتاريخ . ب أغسطس 190V 190 عندما

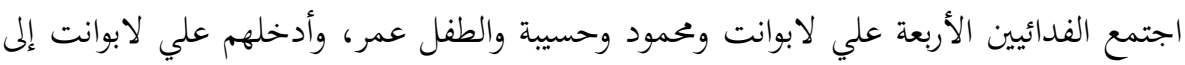

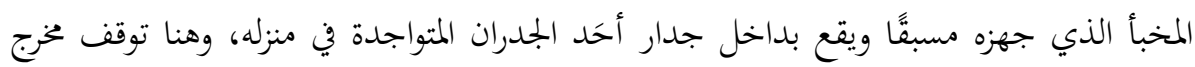

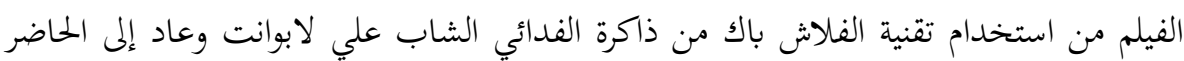

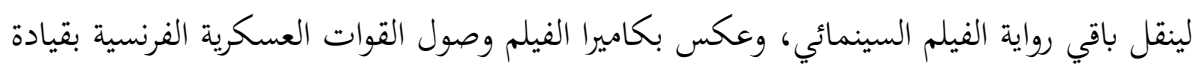

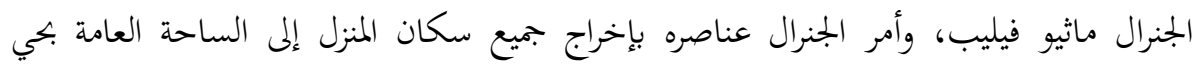

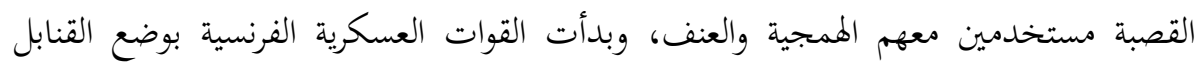

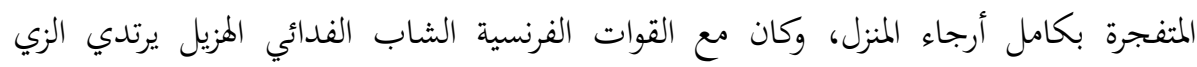

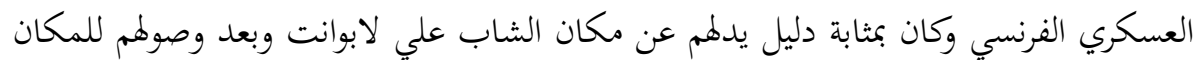

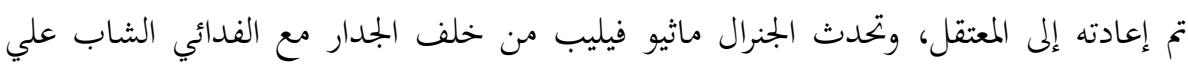

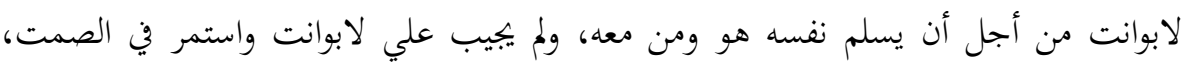

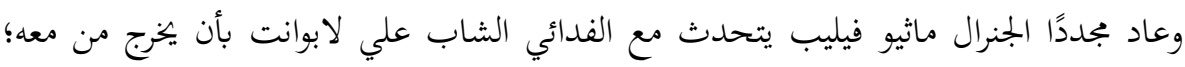

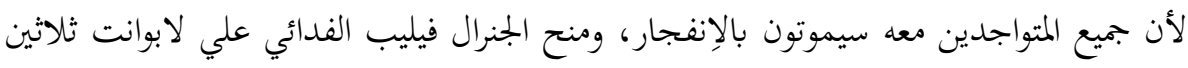

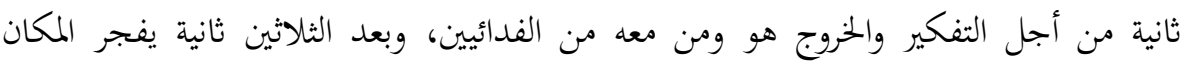

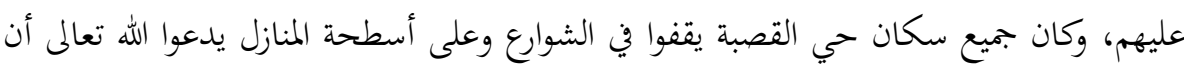

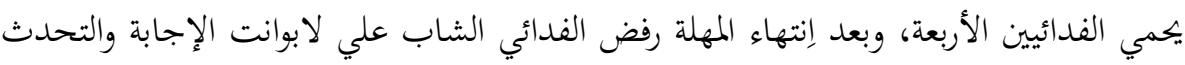

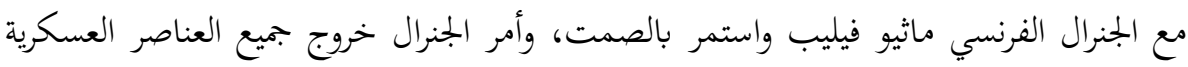

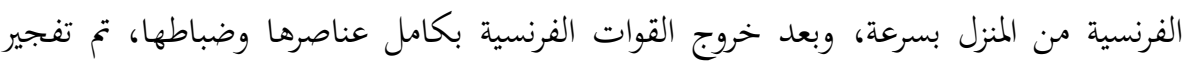

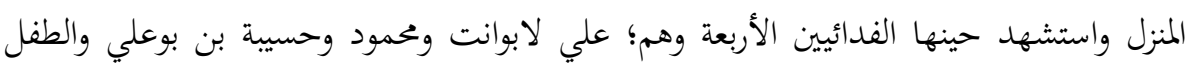

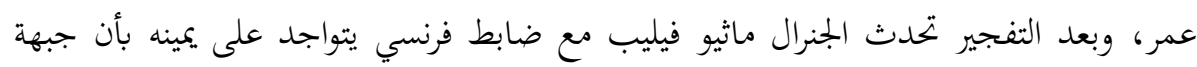

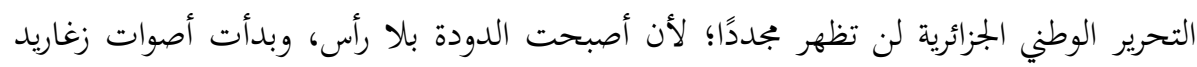

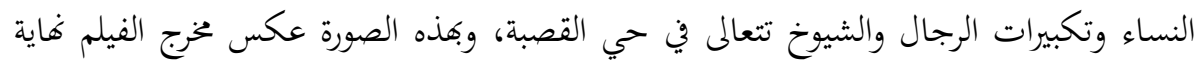

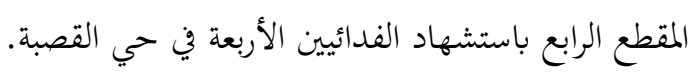

نهاية الفيلم: حاول المخرج أن يصنع لفيلمه غاية مفتوحة عبر عدة مشاهد وثائقية

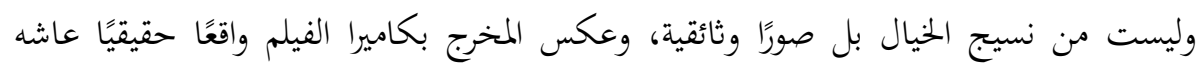


الشعب الجزائري سنة 190V، عندما إدراك معنى الحرية والاستقلال وأصبح مطلبًا أساسيًا

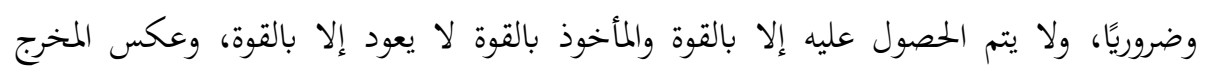

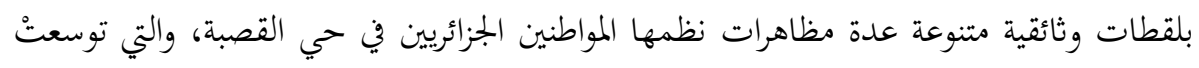

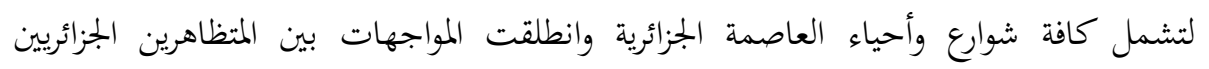

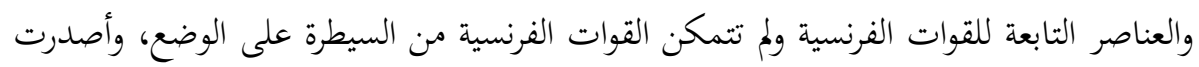

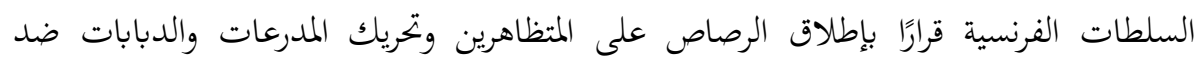

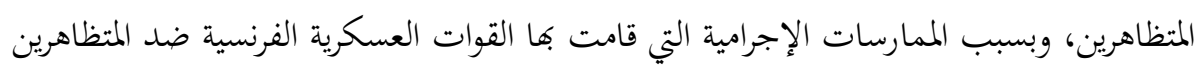

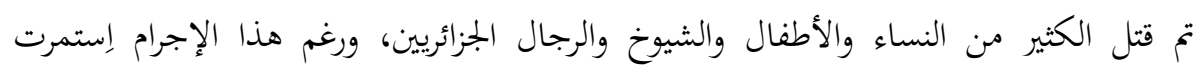

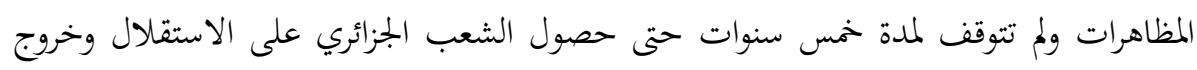

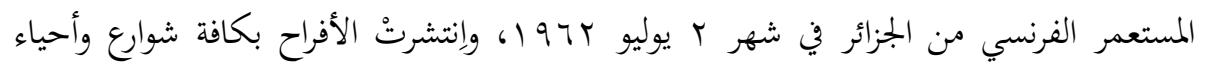
المدن الجزائرية وظهرت سمة السرور والبهجة على وجوه كافة المواطنين الجزائريين فرحين بالاستقلال، وبهذه الصورة عكس مخرج الفيلم فاية الفيلم الروائي معركة الجزائر.

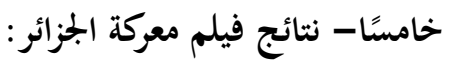

إن مخرج الفيلم صور الفترة التاريخية التي عاشها الشعب الجزائري لمدة ثلاثة أعوام، وبدأ

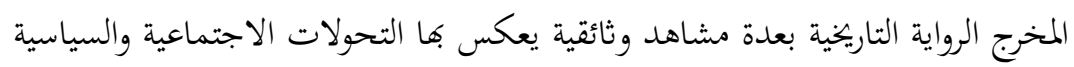

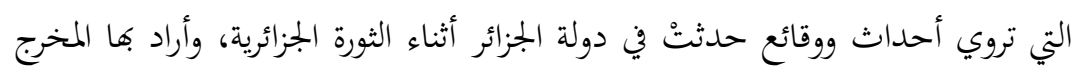

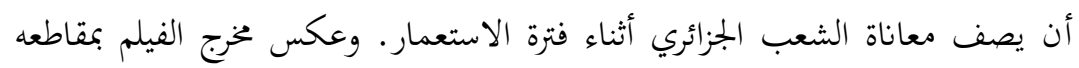

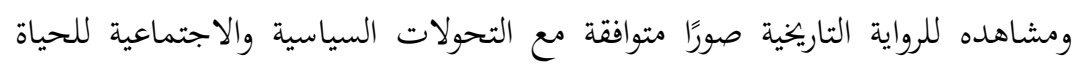

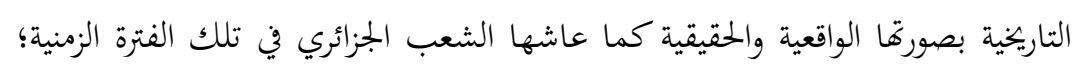

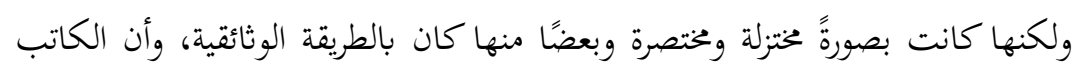

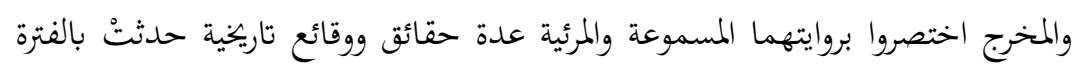

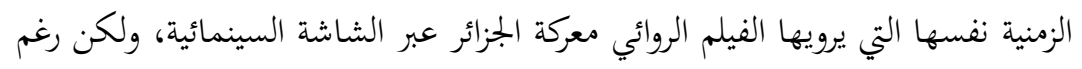

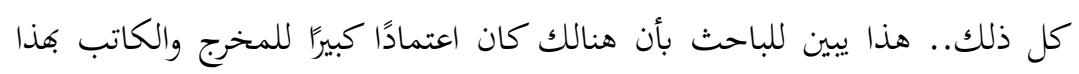


العمل السينمائي الروائي على الحقائق التاريخية المكتوبة والموثقة، بتجسيدهما

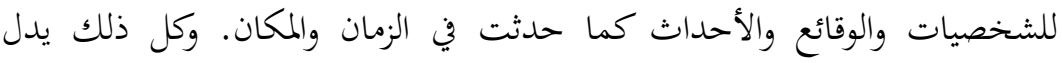

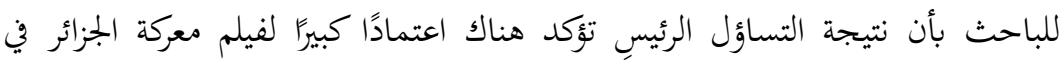

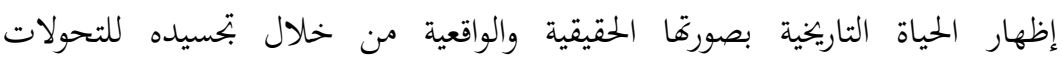
الاجتماعية والسياسية.

ا. إن مخرج الفيلم أراد أن يجسد بروايته أهم الشخصيات الحقيقية التي تتحدث عنها الرواية

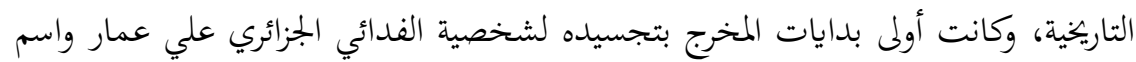

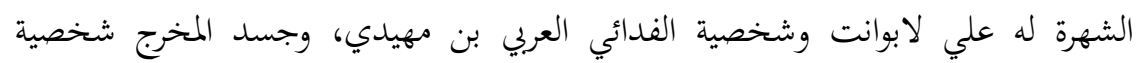

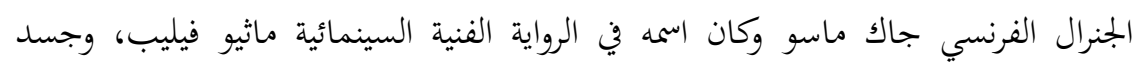
شخصية الفدائي الهادي جعفر، وجسد المخرج شخصيات عديدة من الأبطال الجزائريين

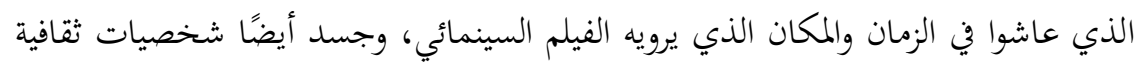
عديدة لمواطنين جزائريين، ويرى الباحث بأن كافة الشخصيات المجسسَّدة في العمل السينمائي هي شخصيات حقيقية عاشتْ في الجزائر بالفترة الزمنية نفسها التي جسدها لفئ الفيلم الروائي.

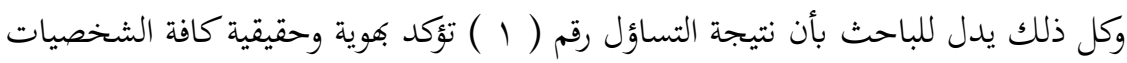
التاريخية بفيلم معركة الجزائر.

r. إن مخرج الفيلم أراد عبر روايته التاريخية إظهار أهم القضايا التي تناولتُ التحولات

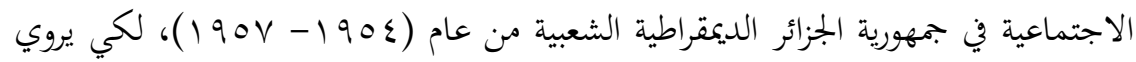

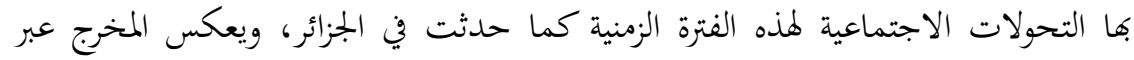

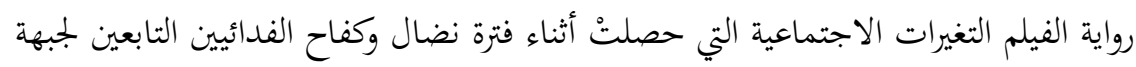

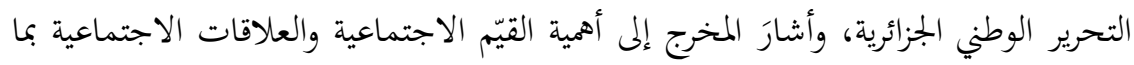

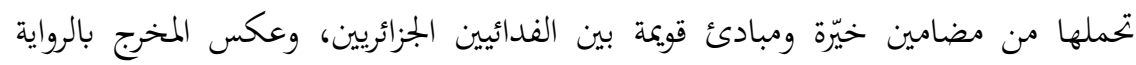

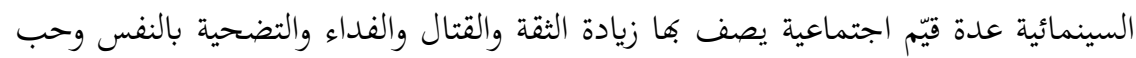

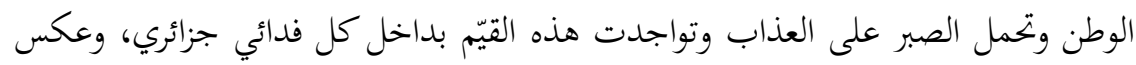

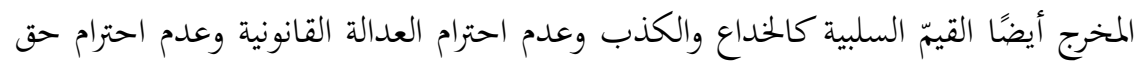

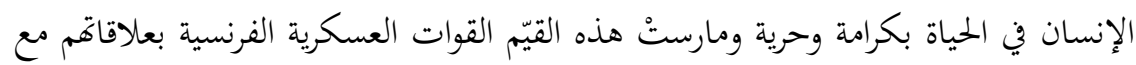


المواطنين الجزائريين من خلال الاعتقالات التعسفية والتعذيب حتى الهلاك

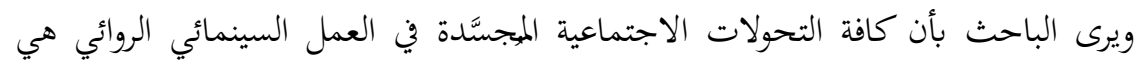

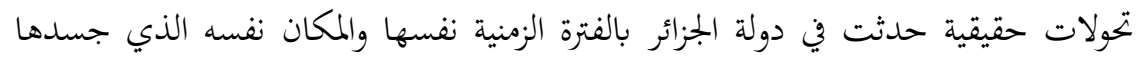

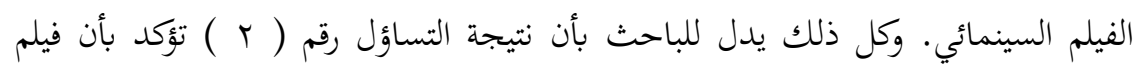

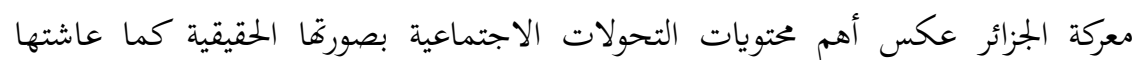
جمهورية الجزائر بالزمان والمكان.

r. إن مخرج الفيلم أراد عبر روايته التاريخية إظهار أهم القضايا التي تناولتْ التحولات السياسية

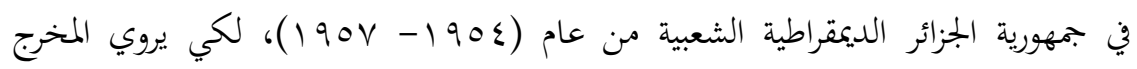

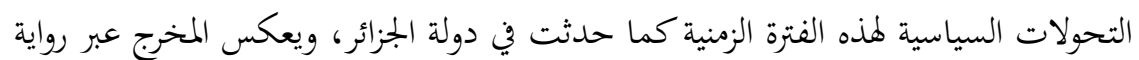

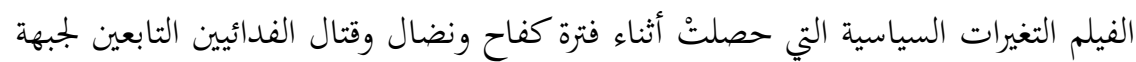

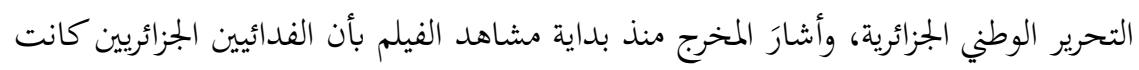

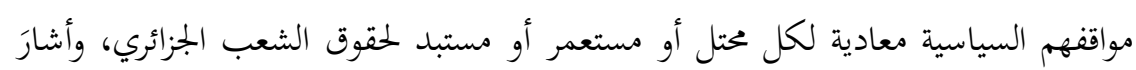

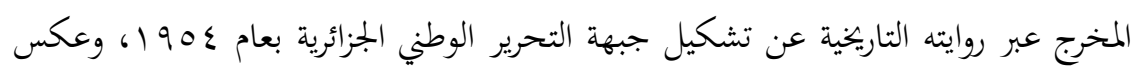

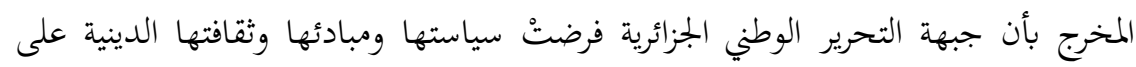

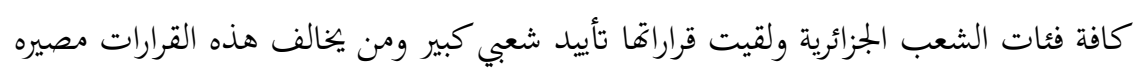

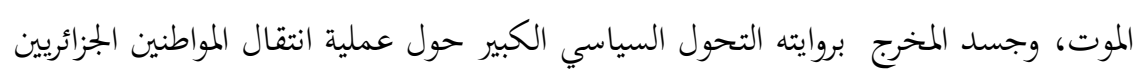

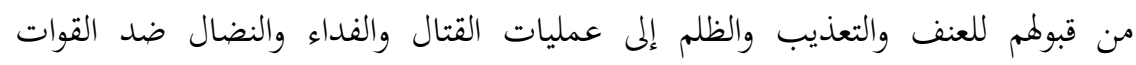

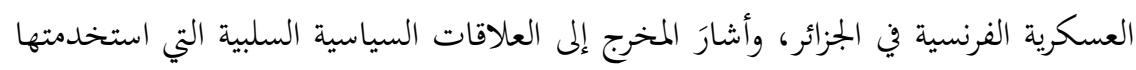

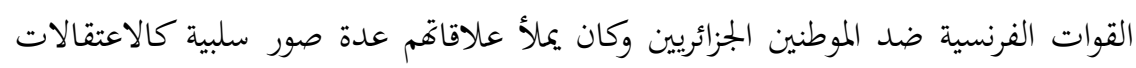

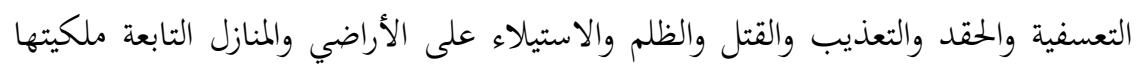

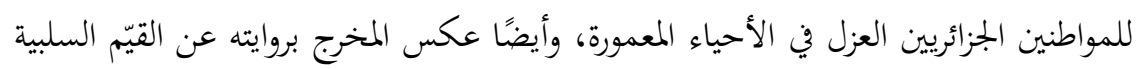

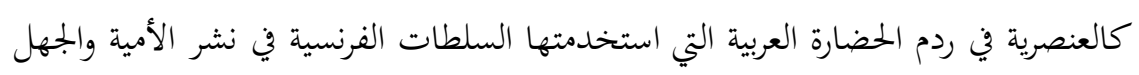

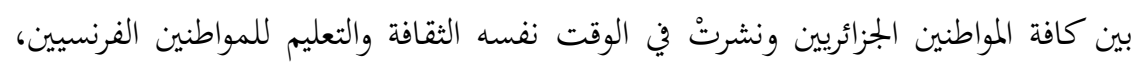

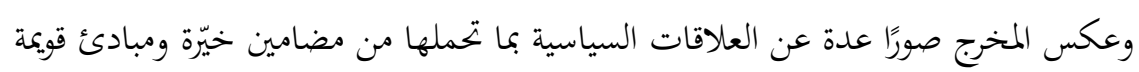

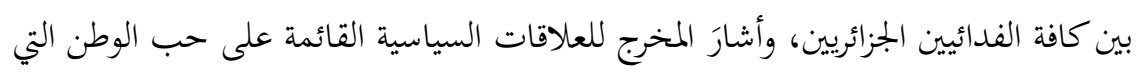


مارسها الفدائيين الجزائريين بعملياتم في القتال والفداء والنضال ضد القوات الفرنسية وألحقوا بالفرنسيين خسائر كبيرة، ويرى الباحث بأن كافة التحولات السياسية المجسسَّدة في العمل السينمائي الروائي هي تحولات حقيقية حدثت في دولة الجزائر بالفترة الزمنية نفسها والمكان

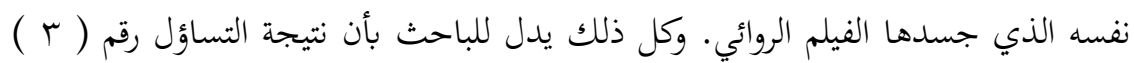

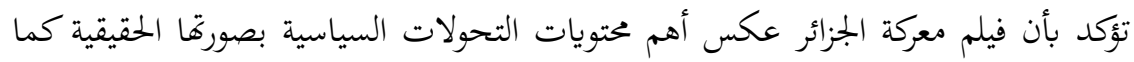
عاشتها جمهورية الجزائر بالزمان والمكان.

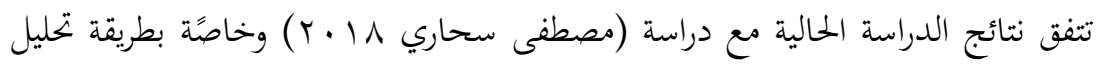

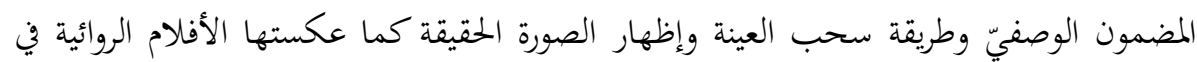

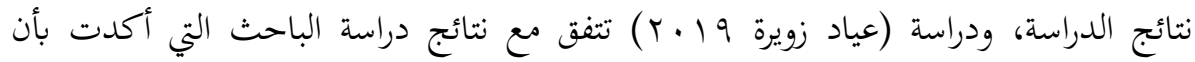

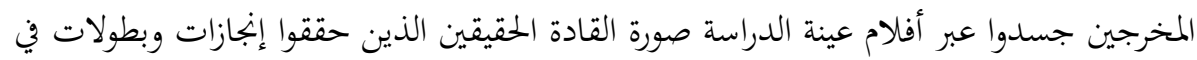

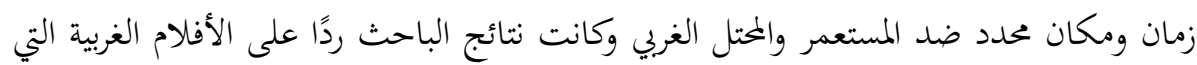

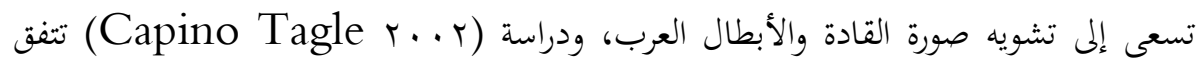
وخاصًة بطريقة إظهار الصورة التاريخية الحقيقة وتوافقها مع الواقع المجسسَّد كما عكستها الأفلام الروائية التاريخية في نتائج الدراسة.

وطبقاً لتفسير قضية الدراسة الحالية في ضوء نظرية الاستشراق، يؤكد الباحث بحسب

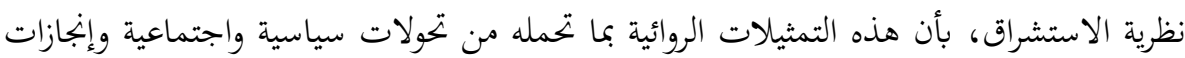

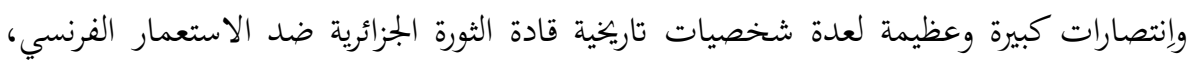
وجاءت نتائجها لهذه الدراسة مخالفة عن نظرة المستشرقين السلبيين عن الشخصيات التاريخية

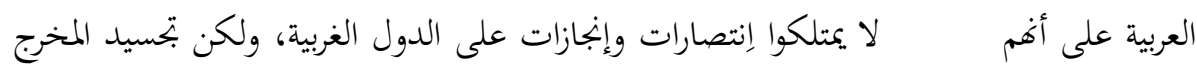

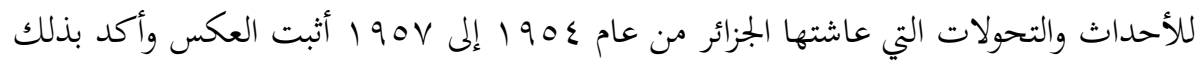
عبر تصوير الإنتصارات العربية على الدول الغربية بعدة أحداث ووقائع من خلال الزمان وان والمكان المان

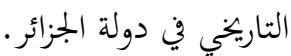




\section{توصيات الدراسة}

إن هذه الدراسة استخرجت عدة نتائج بشقيها التطبيقي والنظري، لذلك يضع الباحث ججموعة من التوصيات، ويأمل أن تقوم الجهات المعنية في القطاعين العام والخاص وخاصةً

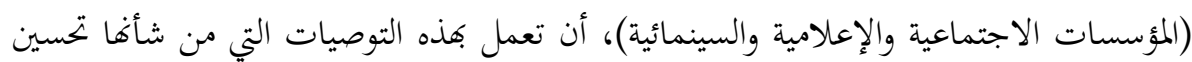

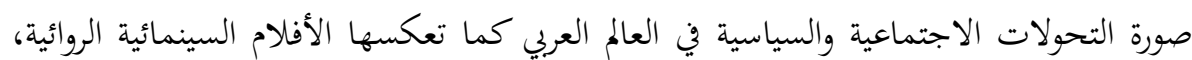

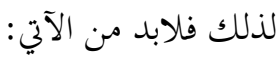

1 - زيادة اهتمام المخرجين والمؤلفين بزيادة عدد المراجع والمصادر الموثقة الخاصة بالرواية

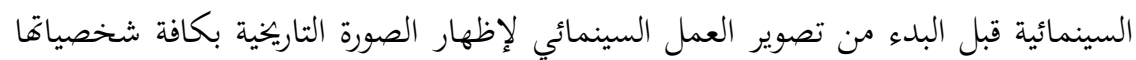
ووقائعها وأحداثها.

Y- رصد جائزة مادية ومعنوية لأفضل عمل سينمائي روائي يعمل على إبراز الصورة التاريخية الإيجابية للتحولات السياسية والاجتماعية لإحدى البلدان العربية.

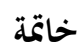

تبين للباحث من خلال تحليله لفيلم معركة الجزائر بأن التحولات السياسية والاجتماعية

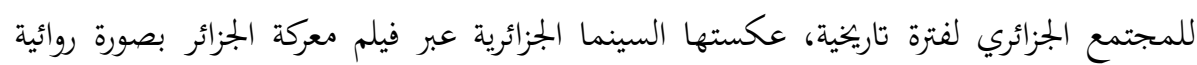

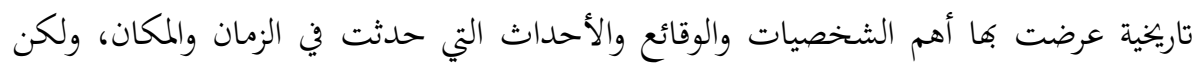

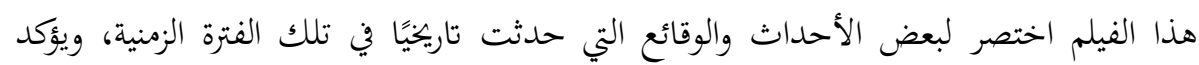

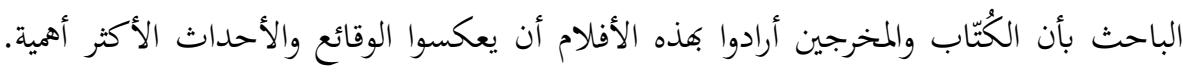

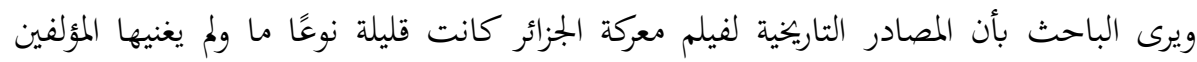

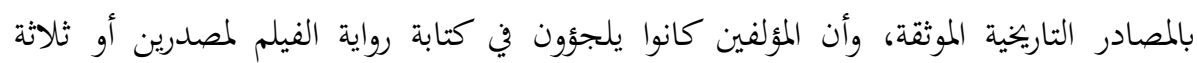
مصادر أو لمصادر عامة تتحدث عن أحداث الروائية التاريخية لفترة زمنية مليئة بالأحداث

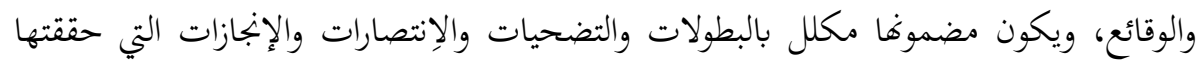

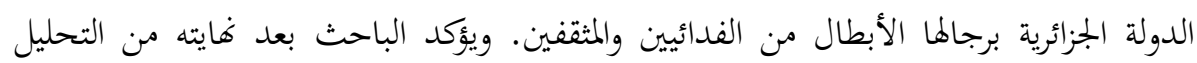

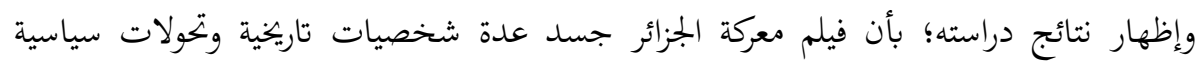


واجتماعية عاشها الشعب الجزائري سياسيًا واجتماعيًا، ويؤكد الباحث حول توافق أسلوب

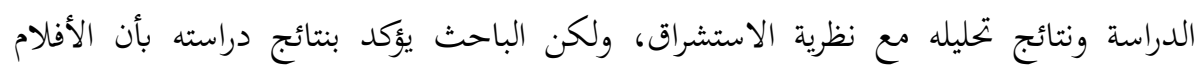

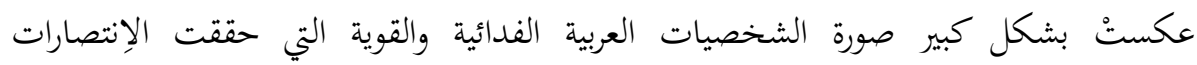

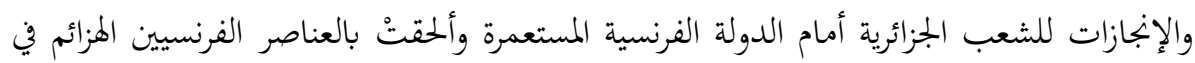

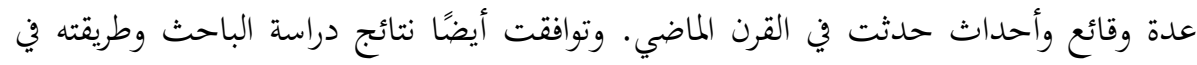

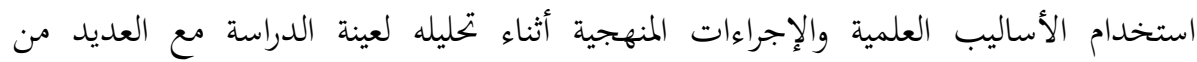

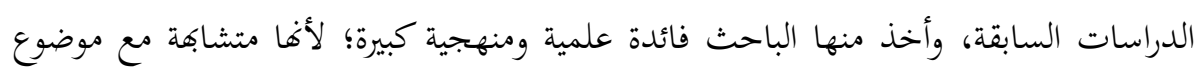
دراسته التي درسها وطبقها العديد من الباحثين السباقين لمذا النوع من الموضوعات العلمية. 
1- أحمد، فرج السيد. (99 1). الاستشراق: الذرائع-النشأة-العتوى. الرياض: دار طويق.

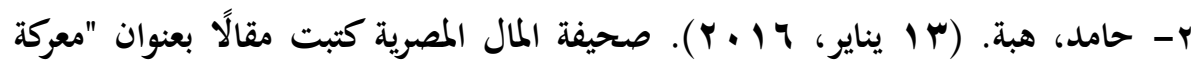

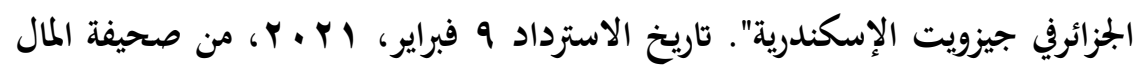

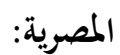

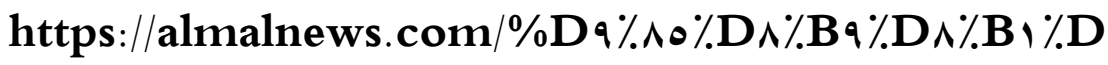

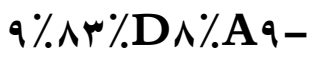

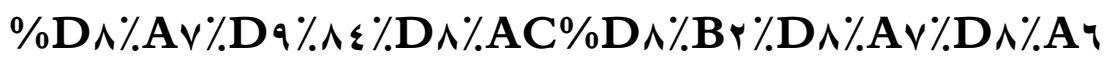
$\% \mathrm{D} \wedge \% \mathrm{~B}$ - $\%$ Da $\% \wedge, \% \mathrm{D} q \% \wedge \mathrm{A}-$

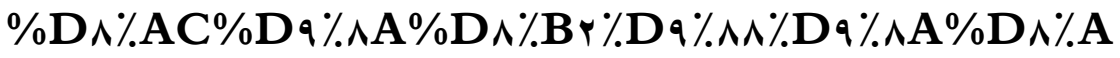
A-

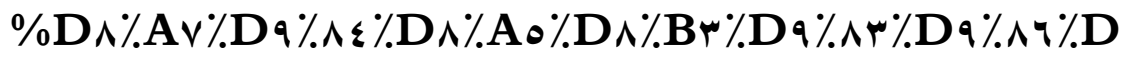

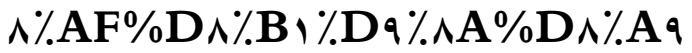

ץ- زويرة، عياد. (9 ( + ). السينما التسجيلية وصورة نضال الجُتمع الجزائري: فيلم الجزائر

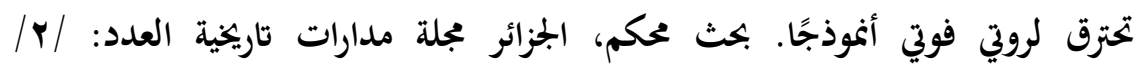

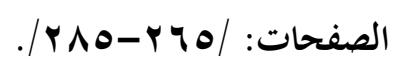

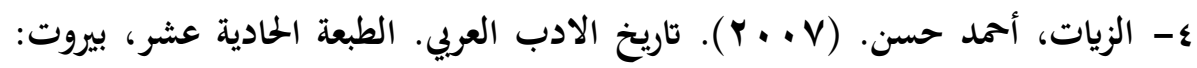
دار المعرفة.

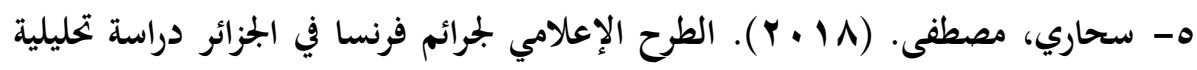

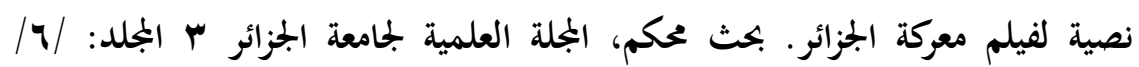

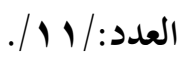




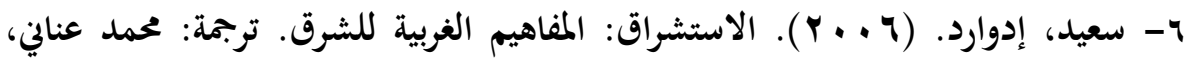
القاهرة: دار رؤية للنشر والتوزيع.

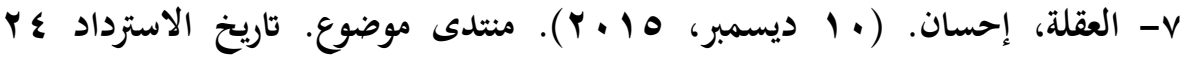
أكتوبر،

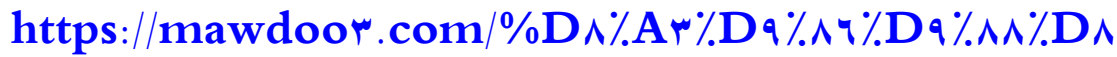
$\% A \vee \% D \wedge \% B q \_\% D \wedge \% A \vee \% D q \% \wedge \varepsilon \% D \wedge \% A r \% D q \% \wedge \uparrow \% D q \%$ $\wedge \varepsilon \% \mathrm{D} \wedge \% \mathrm{~A} \vee \% \mathrm{D} \uparrow \% \wedge$ ๑

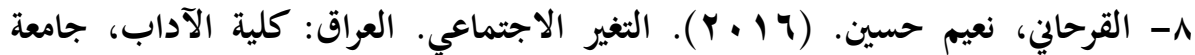
بابل.

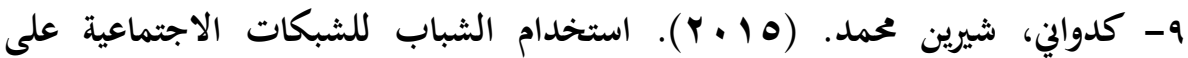
الإنترنت وعلاقته بالتحول الديمقراطى فى مصر. رسالة دكتوراه منشورة، قسم الإعلام،

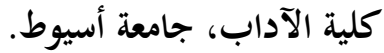

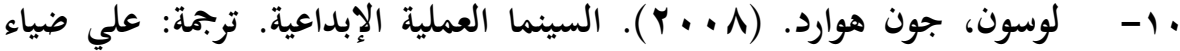
الدين، بغداد: دار الشؤون الثقافية العامة.

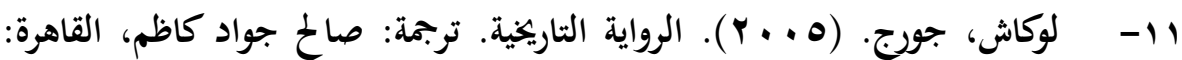

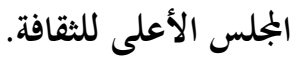

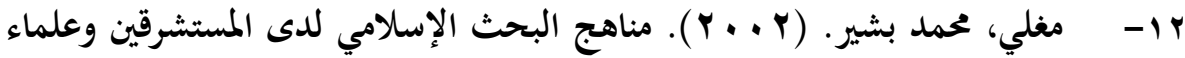
الغرب. الطبعة الثانية، الرياض: مركز الملك فيصل.

$$
\text { المراجع الأجنبية }
$$

J. $(r \ldots r)$. 'Cinema and the spectacle of ،Capino -1 Colonialism: American Feature Film and coloial 
التحولات الاجتماعية والسياسية في الجزائر كما يعكسها الفيلم السينمائي الروائي...العدد الثالث والثلاثون

Philippines: $\mid \wedge ৭ \wedge-19 \wedge 9^{\prime}$. Evanston: PhD thesis:

Northwestem University. 